\title{
"PERESTROIKA": nuevo modelo para el mismo sistema y nuevas relaciones entre distintos sistemas
}

\author{
Francisco Javier Ibisate
}

\begin{abstract}
PERESTROIKA', dirá M. Gorbachev, significa "revolución", pero no se trata de una "revolución en rojo mayor" que busque destruir al contrario; es una revolución más ditícil, en cierto sentido "revolución con bandera blanca" que busca un diálogo de acercamienlo para reconslruir to que juntos hemos destruido o amenazamos destruir. En lo que llamamos "desarrollo y carrera al desarrollo" descubrimos hoy, al hacer el balance del siglo, que encierra una elevada dosis de inseguridad y de potencial destructivo. Las conversaciones en Reykjavick, Ginebra... sobre el desmantelamiento de misiles son o pudieran ser un intento por cambiar el rumbo de una historia que no lleva a ninguna vicloria sino al "aniquilamiento de la humanidad" (p. 160). Debido en parle a la rapidez con que los medios de comunicación nos intorman de los sucesos mundiales, y debido sobre todo a los mismos hechos que son el tema de información, lomamos conciencia de que nuestro mundo está colmando su tasa de conflictividad $\theta$ inseguridad. El istmo centroamericano, pequena parte del planeta, es un bolón de muestra de esa macro-conflictividad. Para nosotros lambién se ha escrito Perestroika.
\end{abstract}

La "revolución" más dificil, sin la cual no puede haber reestructuración del mundo, es la que lenemos que realizar en nuestras posiciones mentales, en nuestras teorias que lácilmente adquieren la rigidez de un dogma. Es necesario constrastar la unilateralidad de nuestras posturas ideológicas con las exigencias históricas de una humanidad interdependiente. Esta es una de las tesis revolucionarias con que Gorbachev concluye su obra. "En el mundo hay una gran sed de mútuo entendimienlo y comunicación. Se siente entre los políticos, adquiere impulso entre los círculos intelectuales, los representantes de la cultura y la opinión pública en general. Y si la palabra rusa PERESTROIKA ha sido 
fácilmente asimilada en el léxico intemacional, se debe a algo más que interés por lo que sucede en la Unión Soviética. El mundo entero necesita reestrucluración, es decir, desarrollo progresivo, un cambio fundamental. La genle lo siente y lo comprende. Tienen que encontrar su rumbo, captar el problema dominante de la humanidad, darse cuenta de cómo deben vivir en el futuro. La reesinucturación es un imperativo para un mundo inundado con armas nucleares, para un mundo dominado por serios problemas económicos y ecológicos, para un mundo abrumado por la pobreza, el alraso y la enfermedad, por una raza humana que entrenta ahora la urgente necesidad de asegurar su propia supervivencia... Queremos que la libertad reine finalmenle en todas partes del mundo en el próximo siglo. Queremos competencia pacífica entre diferentes sislemas sociales para desarrollar y alentar la cooperación mútua antes que las confrontaciones y la carrera armamentlstica. Queremos que los pueblos de cada país disfruten de la prosperidad, la salud y la felicidad. Esle carnino tiene su origen en un mundo no violento, libre de armas nucleares. Nos hemos lanzado por este camino y llamamos a otros países y naciones para que sigan el ejemplo" (pp. 299-300).

Estos párralos finales, que sin duda suenan a algo novedoso, resumen un conjunto de propuestas o posiciones de cooperación, antes que confrontación, entre los dilerentes sistemas sociales. Es una nueva élica política y económica de acercamiento, que ponga fin a la ética de dominación. Eslo se aplica a las dos partes de Perestroika, al "mensaje a mi pais" y al "mensaje al resto del mundo". Perestroika es una obra llena de sinceridad y de realismo histórico, y por ello aparece como "un signo de esperanza en medio de la gran crisis económica mundial"'2. Realismo y sinceridad en la primera parte, no sólo porque $M$. Gorbachev haya confiado a "editoriales norteamericanas" la publicación de estas páginas que airean los problemas internos de la URRS ("queremos que nos comprendan..") sino porque el premier soviético ha dicho lo que muy pocos se hubieran atrevido a decir. La misma sinceridad, hasta con nombres y apellidos, encontramos en el Informe al Pleno del Partido (256-1987) 3 . Para entender el mecanismo de funcionamiento, los logros y las fallas de las llamadas economias socialistas asl como su polencial de realización, ambas publicaciones nos brindan una realista información (glasnol), que brillaba, por su ausencia, en anteriores publicaciones oficiales o "manuales de exportación". No es de extrafiar que la "perestroika" suscite oposición y actos de contraperestroika al interior de la URSS. Sobre este aspecto volveremos más adelanle, escuchando al propio M. Gorbachev.

Realismo y sinceridad sorprendente encontramos en la segunda parte, con razón litulada "el pensamiento nuevo y el mundo". Pensamiento nuevo ¿de quién?; ¿de la dirigencia soviética, de los sislemas 
económicos, de la humanidad en bloque?... Creo que el titulo da lugar para que los politólogos, los economislas y los hisloriadores amplien estas respuestas. Lo cierto es que en esos tres párrafos finales de Perestroika hay muchos mensajes "novedosos" o ¿revolucionarios?... "La raza humana enfrenta ahora la urgente necesidad de asegurar su propia supervivencia.... en un mundo no violento, libre de armas nucleares... El mundo enlero necesita reestrucluración, es decir un desarrollo progresivo, un cambio fundamental... Queremos competencia pacífica entre diferentes sistemas sociales para desarrollar y alentar la cooperación mútua, antes que las conirontaciones y la carrera armamentistica... Nos hemos lanzado por esle camino y llamamos a otros paises y naciones para que sigan el ejemplo"... Perestroika recoge aqul un clamor de toda la humanidad, sobre todo esa humanidad que se llama el "lercer-mundo".

No es esta la "Mano de Moscú" a que la propaganda occidental y nuestros medios de comunicación locales nos lienen acoslumbrados; los mismos procesos electorales y los comportamientos gubernamentales dentro y los "desde fuera" nos muestran lambién lo lejos que eslamos de esa capacidad de diálogo entre sistemas sociales diversos. Hay sus razones afectivas e ideológicas, y hay también sus razones hislóricas que han sido expuestas, lo veremos en la obra de Gorbachev. Porque Perestroika admite, por lo menos dos formas diferentes de lectura; y de hecho asi se está leyendo. Habrá quienes lean primero la primera parte subrayándola, pasando luego a la segunda parle sin concederle mayor credibilidad, o en todo caso la ven como un forzado intento de publicidad que no convence. ¿Cómo se hace esta leclura?Oigamos a M. Gorbachev: "Exisle la opinión de que fue necesaria (la Peres(roika) por el estado desastroso de la economía soviética y que signitica desilusión del socialismo y una crisis de sus ideales y tines últimos..." (p. 9) Para muchos leclores, que detienen su leclura en los puntos suspensivos..., esla hipótesis queda más que contirmada en la subsiguientes páginas que plantean los problemas derivados de la contracción económica (pp. 17-20) y la "gradual erosión de los valores ideológicos y morales de nuestro pueblo" (pp. 20-25). El resto de esta primera parte suministra citas selectivas para reconfirmar el aire de superioridad occidental. "Por su boca muere el pez": el socialismo está en crisis económica y moral, y qué mejor testimonio que el de la dirigencia soviética para convencer a convencidos. Con esta lectura unilateral ya no le queda nada de "nuevo pensamiento" al mensaje dirigido al mundo de hoy. Es simple publicidad, ulopia, ganas de recibir aplausos, y sobre todo láclica de espera mientras se intentan componer los problemas internos. Si sólo se da le a una lectura selecliva de la primera parte queda diluido todo el inlenlo de Gorbachev y "Perestroika" puede archivarse en nuestras libreras como un anexo confirmatorio de las tesis de Ludwig von Misses. No está demás trasladar una sensata réplica a esla posición: 
"No deja de ser algo pirtoresco, en primer lugar, que en plena crisis de la economia norteamericana se perciban los lenómenos de un modo tan triunfalista y unilateral. Lo manifiesto es que ambas superpotencias $-\mathrm{y}$ el conjunto del mundo en menor grado - han estado soportando una militarización económica, científica y tecnológica de la cual empiezan a resentirse visiblemente... Temo mucho que con tales lecturas no se pueda avanzar gran cosa en la recepción y debale de las propuestas de Gorbachev"4.

Perestroika se puede, y se deberia leer desde la segunda parte, desde el epílogo de la obra, y entonces aparece como un signo de esperanza, de manera especial para los paises del tecer-mundo. Desde esta óptica, la primera parte del "mensaje a mi pais" aparece como una de las zonas del planeta que también hay que reestructurar para el mayor bien de toda la humanidad. En las mismas techas y por semejantes razones el Papa Juan Pablo II en su reciente encíclica, "La preocupación social de la Iglesia" (30-12-1987) - y que hasta el momento ha tenido escasa resonancia en nuestro pais- expone a lodos los hombres de buena voluntad el gran clamor de la humanidad: "la páz y el desarrollo", que es el nuevo nombre de la paz. El discurso no queda al nivel de abstracciones éticas sino aplicadas a elementos concretos del sistema internacional del comercio, al sistema monelario y financiero mundial, a las Iransferencias de tecnología, a las organizaciones inlernacionales, a la carrera armamentística, a la deuda externa del tercer mundo..., y a la culpabilidad que, por acción u omisión han contraído los dos grandes sistemas económicos en la gestación de este desorden económico mundial. Ambos documentos fechados a fines de 1987, la Perestroika del Kremlin y la enciclica del Vaticano tocan aspectos comunes, y donde Gorbachev habla de la "colaboración de todos los sistemas" Juan Pablo II habla de la "solidaridad de todos los pueblos". Dos documentos que pueden complementarse, pero que reclaman la lercera "perestroika" del Occidente, especialmente de quien parece ejercer el liderazgo desde este lado del Allántico. Para ello es menester leer con objetivad, y no superioridad, los cinco capitulos del "Mensaje al mundo": ¿Cómo vermos el mundo actual?; la reestructuración en la URSS y el mundo socialista; el tercer mundo en la comunidad internacional; Europa en la política exterior soviélica; problemas del desarme y relaciones soviético-norteamericanas.

Se trata de una propuesla de diálogo y reflexión participada. "Debemos reunirnos y discutirlo. Debemos abordar los problemas con espiritu de cooperación, más que de animosidad. Me doy perfectamente cuenta de que no todos estarán de acuerdo conmigo. En realidad tampoco yo estaría de acuerdo con todo lo que los otros dicen sobre diversos temas. Eso hace que el diálogo sea lo más importante. Y esle 
libro es mi contribución a ello". (p. 7) Creo que desde esta amplitud mundial tiene que leerse la primera parte. Gorbachev y la dirigencia soviética saben que han iniciado, o más bien reiniciado, una "ardua tarea". Perestroika signitica gradualmente "relorma-reestructuración-revolución" y Gorbachev prefiere que se le entienda como una "revolución" al interior del socialismo. El proceso dialéctico no termina con el advenimiento del sistema, y el "glasnol" exige sacar a la luz los problemas, descubrir las causas e inlentar soluciones sin duda contlictivas. Mala postura adoptan también, dentro y fuera de la URSS, los críticos de la "derecha socialisla" que acusan a Perestroika de "socavar las bases del sistema" y ven en ella signos de debilitamiento de los ideales de lucha-rendición. Silenciar los problemas no es la mejor solución de los problemas y limitarse a repetir panegíricos oficialista a la "unión de hombres libres que trabajan utilizando medios de producción comunes" no es la más hábil publicidad en un mundo donde tarde o temprano salen a la luz las prolestas de los disidentes y los Iran-Gale de lodos los sistemas. Si perestroika significa revolución es porque hay "algo que cambiar".

En arlículo anterior, respondiendo a ¿porqué era necesaria una perestroika?5 hice brevemente referencia a la siluación de los movimienlos de la izquierda occidental, sobre todo europea, que sienten algo dillcil presentar a sus "seguidores" como modelo de socialismo el sistema tal cual se eslaba eslableciendo en los paises del Este, en sus rasgos políticos y económicos; "esos modelos no son capitalismo, no son socialismo; son olra cosa", si bien haya diferencias al definir esa "otra cosan. Siguiendo la evolución del modelo soviético, autores filomarxistas como M. Dobb, P. Sweezy, Ch. Bettelheim, E. Mandel... que en las décadas de 1930 y $1940 .$. defendieron la necesidad de un modelo centralmente planificado, han pasado a ser, junto con olros muchos autores, duros criticos de la rigidez burocrática y política que ha venido oponiendo las mayores resistencias a los repetidos intentos de hacer "perestroika" dentro y fuera de la URSS. Se Irala de autores y de criticas que no buscan la desaparición del sistema, sino su reconducción hacia objetivos sociales y democrátlcos. Sin duda esta amplia crítica que emana del campo socialista internacional ha podido contribuir positivamente a la génesis de Perestroika; el tema de las estrucluras, un tiempo motrices, que se convierten en "freno del sistema" es una premisa central en la primera parte de perestroika. Con lodo hay que decir que perestroika se gesió desde deniro, o como dirá Gorbachev "nace de arriba porque nace de abajo" (pp. 60-65).

Al interior de la URSS, luego de la muerte de $L$. Brejnev, los análisis económicos y sociológicos del equipo de Novosibirsk, 1983, (sección siberiana de la Academia de Ciencias), con A. Aganbeguian y $T$. Zalauskaya al trente, son claramente el punto de apoyo a la reforma de 
Gorbachev. Los problemas de la "glasnot" en cuanto transparencia, la importancia del factor humano, el interés por el trabajo, la justicia social, la democratización de la sociedad, el pluralismo de las candidaturas, la retorma de la justicia, la recuperación de la conciencia moral y el poner fin al dogmatismo sociológico, fueron publicados con ocasión del "relevo polltico" y M. Gorbachev hizo de ellos la plataforma de su polílica de reestructuración 6 .

Hay razones históricas de carácter económico, social y político, que dan razón a la génesis de perestroika en la URSS, y que M. Gorbachev las expone sin recortes ni silencios; una autocrítica con conciencia de auloreconsırucción. El llamado al diálogo crítico, con miras a una reconstrucción de un mejor orden mundial, lendria menor credibilidad y se tomarla como publicidad o láctica de espera, si no viniera precedida por la propia aulocrítica nacional. Es todo el mundo, todos los sistemas los que necesilamos de la autocritica. Limitarnos a decir que "en el socialismo hay crisis"... y quedarnos en los puntos suspensivos es perder la oporlunidad y la necesidad de reflexión que nos brinda Perestroika, y lambién Juan Pablo II, si es que algo tenemos de cristianos.

Por supuesto no se trata de hacer aqul un resumen de las dos partes de Perstroika, y ello por varias razones. Lo primero, porque más vale leer directamente Perestroika que un mal resumen de esla obra. Me parece que cada lector se convierte en el mejor propagandista del libro, y las "editoriales norteamericana" van a hacer buen negocio con M. Gorbachev, enire paréntesis nombrado "el hombre del ano en los EE.UU"'. En segundo lugar, Perestroika es una obra pluridisciplinar y pluridimensional, por el contenldo de los capitulos citados; un buen comentario requiere del aporte combinado de las diversas ciencias sociales. $Y$ en tercer lugar, porque en esle campo de los "sistemas económicos", consciente o inconscientemente, uno hace o enfoca el resumen desde los propios sentimientos, a veces simples afectividades, desfigurando el hilo conductor o el escenario mismo en que se desarrolla la obra. Quien escribe estas líneas sabe que no está inmune de esta lentación, y prefiere llanamente invilar a la lectura de esa obra, antes que a la leclura de estas páginas. Hecha la advertencia y dado que a los "sistemas económicos" los entallamos dentro de tan diversas "teorias de convergencia y dlsconvergencia, dependencia e inlerdependencia, coexistencia"... y otras que iremos inventando, podemos reflexionarlas un poco dentro de ese marco histórico de donde viene y a donde quiere llevarnos la Perestroika de M. Gorbachev.

\section{De la Teorla de la "Convergencla" a la Teorla de la "Irre- conclbllidad"}

La situación de crisis y desequilibrio generalizado que nos describen, 
entre otros documentos, la Perestroika de M. Gorbachev y la Enciclica de Juan Pablo II se debe en gran parte a las posiciones ideologicas y prácticas que los grandes sistemas económicos, sus naciones, han sostenido entre si en las últimas décadas. Cuando $M$. Gorbachev invita en su epílogo a una "competencia pacífica, a alentar la cooperación mútua, antes que las controntaciones", en cierto sentido está proponiendo una "convergencia" de los bloques y sistemas hacia un objelivo común: la paz y el desarrollo, sobre todo en el lercer mundo. Pero al mismo tiempo está recordando que no se ha dado tal convergencia, sino confrontaciones crecientes y el trágico resultado de una "convergencia en la carrera armamentistica".

Un articulo publicado en ECA, 1982, llevaba por título una pregunta, a primera vista ociosa y sin sentido: "La crisis de 1970-1980..., ¿es realmente una crisis?" - Quién lo puede poner en duda. Sin embargo la intención del artículo era mostrar que esa crisis ya se habla gestado desde antes, porque al tinalizar la segunda guerra mundial y tirmarse la paz, "se eslaba firmando otra clase de guerra"7. Es cierto que entre 1950 y 1970 "el producto mundial se habla cuadriplicado"; nunca en la historia pasada se habia logrado tal incremento en el espacio de veinte anos. Pero al levantar la cubierta de esa "máquina tragamonedas" (la producción bruta), que suma monelariamente valores que habrla que restar, se descubria que más de la milad era "producción para la destrucción", relegando el desarrollo social. El siglo veinte es un siglo de "blanco y negro", con intentos de inlroducir otros colores. Pese a esta estructura o composición del Producto Mundial, afloran en la década de 1960, con cierlas variantes, las llamadas "teorlas de la convergencia"8. No hay hugar aqul más que a una breve síntesis o referencia. Se trata de interpretar, con el espacio concedido por veinte anos más de historia, si los hechos lundamentan una "convergencia" o más bien la "conlrontación" de que nos habla Perestroika.

Es cierto, a partir de 1945, que en el grupo de naciones desarrolladas, aunque destruidas por la guerra, adscritas al bloque capitalista se dan una serie de transformaciones imporlantes, quizás estructurales en algunos palses. La influencia de la teorla keynesiana, las grandes recesiones de la crisis, guerras, reconstrucción, más la confrontación con otro sistema que quiere mostrar sus capacidades de mayor autodesarrollo económico y social..., pueden servir de explicación de los cambios observados. Algunos de estos signos, de acuerdo al Premio Nóbel J. Tinbergen, serian: la extensión del sector público cuantilativa y cualitativamente en amplio sectores de la actividad productiva junto con la creciente participación del Presupuesto Estatal en la Renta Nacional; el incremento de las técnicas de planificación nacional con cierto control de la libre competencia interempresarial, de la tijación de precios y de salarios; po- 
If́tcas regionales de desarrollo, es decir polfticas de deconcentración geográflca y creación de nuevos polos de desarrollo sobre la base de amplios proyectos de trabajo públicos $\theta$ inversión estatal; extensión de los servicios gratuitos o semigraluitos en las ramas de educación, salud... asl como nolables avances en el campo de la seguridad social... La "mano visible del Estado" - se hace cada vez más patenle cuantitava y cualitativamente con nuevos poderes y políticas económicas.

En el llamado bloque socialista, a partir de 1955 y más especialmente a raiz de la "Retorma Liberman", 1965, con Breshnev-Kossiguin, se observan una serie de cambios interpretados en el occidente como un viraje hacia el capitalismo. En las relaciones entre plan y mercado se incrementa, no sólo la participación de las empresas regionales o sectoriales en la orientación del plan, sino también la autoresponsabilidad en la gestión de la producción que le ha sido encomendada: los parámetros normativos serán la rentabilidad y el beneficio, las solicitudes del mercado empresarial y final, los estímulos materiales o primas, los créditos con el correspondiente tipo de interés y el máximo esfuerzo por reducir los gastos en capital fijo y circulante. "Plan, beneficio y primas" de E. Liberman es un lftulo orientador de la relorma tendiente a instalar un "modelo más descentralizado". Se intenta fortalecer los mélodos de la administración de empresas en la periteria y someter el sislema de planiticación económica y de asignación de precios a cálculos matemáticos y apreciación de los coslos sociales. También en las relaciones externas, los principios de "autarqula" ceden ante la necesidad y ventajas comparativas del intercambio comercial y financiero, incrementándose fuertemente el flujo de exportaciones-importaciones con los paises occidentales, los préslamos en monedas fuertes "convertibles" y poco a poco la "deuda externa" con occidente. En realidad se estaba intentando algo más que una simple adaptación de medidas o políticas aparentemente capitalistas. El ensayo de "deconcentración geográfica de $\mathrm{N}$. Krustchev, donde aflora el problema, hoy más serio, de las "nacionalidades" al interior de la URSS, y sobre todo la citada Reforma Liberman fueron un intento de "hacer perestroika" seguido bien pronto de la reacción contra-perestroika dentro y fuera de la URSS 9 .

Esta serie de signos externos que mostraban una creciente parlicipación del Estado y de la planificación consecuente en las economlas de mercado, y una participación creciente del mercado interempresarial y final en la orientación y control del plan en las economlas planificadas, dió lugar a la aparición de un conjunto de leorias de la "convergencia" o interprelación biológica de la evolución de los sistemas hacia un término común. Simultáneamente el enloque de J.K. Galbraith, basado en las exigencias lecnologicas de la gran empresa moderna, mostraba en forma atractiva los cambios químicos que se estaban realizando al interior de 
estas unidades de producción. En la "nueva empresa", cada vez más anónima y multinacional, los propietarios salen fuera de la empresa: no hay estadio de base-ball que pueda contener a todos los accionistas de las grandes firmas. Quienes las dirigen no son los duenos, sino los managers administrativos, supeditados a su vez a los impulsos innovadores de los "tecnócratas". Grandes empresas y sector público quedan intimamente relacionados: las primeras reciben grandes demandas del segundo, quien a su vez protege a las primeras. Hay olros signos de intercambio: un Director de un Ministerio de Defensa sale de la Dirección de la Ford y viceversa, porque las técnicas directivas son semejantes. Los trabajadores están organizados en "sindicatos" dirigidos universitariamente por técnicos laborales, y las relaciones con la dirigencia queda establecida en convenios formales de mediano y más largo plazo.

También las exigencias de la tecnologia, siempre en posición de plusultra, va conduciendo a un cambio estructural en las economias socialistas, donde el "centro-planiticador" o esfera eslatal tiene que compartir decisiones con los tecnocratas de las industrias y los managers de las empresas. En resumen, razones económico-sociales y exigencias tecnológicas empujaban a ambos sistemas hacia una convergencia, que adicionalmente significaba mayor interdependencia comercial, financiera y tecnológica. La teorla de la convergencia tenla un atractivo psicológico al alejar para un más largo plazo o diluir del todo la profecla de que un sistema serla necesariamente absorbido por el otro.

En el análisis de sistemas económicos hay que distinguir entre la fachada y el mecanismo de luncionamiento interno. Al mismo tiempo otros signos comenzaban a desvirtuar las teorlas de la convergencla, mostrando más bien un reordenamiento de las fuerzas y ejércitos económicos en formación de combale. A partir de la segunda guerra mundial y con relativa rapidez cambia el mapa geo-económico y ge0estratégico en el hemisferio norle, quedando el hemisferio-sur como espectador dependiente. Los "sindicatos de paises", llamados "mercados comunes" acaparan la geografla del hemisferio-norte: mercado común de los EE.UU., mercado común europeo, zona del libre cambio, mercado común de la URSS, mercado común de las repúblicas populares chinas, mercado común de los palses socialistas o consejo de ayuda económica múlua. Surge la pregunta: Los grandes paises ¿son fuertes porque se unen o se unen porque son fuertes? - Al igual que las antiguas flotas mercantiles iban acompanadas de la flota armada, los dos grandes bloques se hacen proleger por adelante y por detrás, el uno con el Pacto del Allánlico y el otro con el Pacto de Varsovia... También en el hemisferio sur surgen una diversidad de los llamados mercados comunes y zonas de libre comercio pero o las uniones no son muy 
fuertes o se les aplica el principio del "divide et impera", mientras escogen en qué flota mercantil y militar se trepan.

La "teoria de la convergencia" comienza a perder significado frente al realismo del "efecto-dominación". La expresión y el enfoque viene prestado a Francois Perroux. ${ }^{10}$. El utiliza este enfoque del "efectodominación" para explicar el desenvolvimiento histórico del sistema capitalista; la intención aqul es darle una amplitud mayor a ambos sistemas. Muy en sintesis F. Perroux lo describe como "la acción irreversible $O$ asimétricamente reversible de la unidad-A sobre la unidad- $B^{n}$ : la unidad-A domina sobre la unidad-B, sin que ésta pueda replicar o lo haga en forma poco sensible. Este efecto-diminación, que invade la hisłoria del capitalismo, dirá F. Perroux, lo podemos encontrar al interior de la empresa entre la dirección y los dirigidos; al interior de la industria donde la empresa lider establece las reglas del juego y distribuye las parcelas del mercado; al interior de la nación donde se imponen los polos dominantes industriales, financieros o portuarios: quien los controla la nación; al interior y al exlerior de las relaciones inlernacionales entre economias y bloques centrales y los países peritéricos. Son Ires los elementos constilutivos del electo-dominación: el "lamano" de la unidad (empresa, región, nación, mercado común); la "cualidad" o importancia del producto-servicio prestado (lecnología, equipo, energía, crédito..., armamento) y el "poder de discusión" derivado de lo anlerior: "suplyeffect, influence-eflect and bargaining-power".

Esle "eleclo-dominacion" parece haber sido el regulador del comportamiento al "interior" de los dos bloques y también en las "relaciones entres" las naciones más representativas de los dos sistemas económicos. Mirando brevemente el lado occidental o bloque capitalista algunos signos pueden fundar esta interprelación. Después de la película "Bienvenido Mister Marshall" parece para sorpresa de Europa el libro de J. Jservan Schreiber: "El desatio americano", 1967; Europa ya no era de los europeos, sino campo abierto a las multinacionales norteamericanas. Los "tecnócratas" de K. Galbraith habian atravesado el Allántico. Europa tenía sus propias monedas, pero a partir de BretonWoods, el regulador monetario era el "patrón-oro-dólar (as good as gold). En el ranking de los P.T.B. nacionales la Exxon y la General Motors aparecian como los países $\mathrm{N}^{2} 16$ y 17 respectivamente por su cilra de ventas, y el volumen de producción de las cinco primeras multinacionales sumaba el $12.5 \%$ del PTB norteamericano. En una más moderna edición de A. Smith el autor afirmaria que la economía de los EE.UU. estaba dirigida "por la mano invisible de las multinacionales". Si A. Smith no luvo tiempo de decirlo, lo ha dicho K. Galbraith: la economia americana está planilicada por las grandes empresas", y las economias de otros paises también... A partir de 1968 ... los vientos comienzan a cambiar de rumbo 
al interior del bloque occidental, donde crecen las insurgencias contra el lider, quien necesita de apoyos con más tenláculos: la trilaleral, los cinco, los siete, los diez grandes, frente al posible poder compensador de las Naciones Unidas. También han podido ulilizarse instituciones financieras internacionales como instrumentos de desarrollo bajo control; al fin y al cabo el FMI es una cooperaliva de accionistas donde dominan más los que colizan más y colizan más porque dominan más. $Y$ frente a las renovadas insurgencias de los paises del tercer mundo conira algunas de estas instituciones, el poder de dominación trata de salvaguardarse con la política del "caso por caso". No hay duda de que a partir de la década de 1970 la serie de entrentamientos contra el gran liderazgo o electo dominación se han venido multiplicando dentro del hemisferio norte y sobre todo desde el llamado lercer-mundo.

Sin alejarnos, sino más bien acercándonos a una lectura de Perestroika también el bloque socialista ha estado actuando en buena medida de acuerdo a las normas del efecto-dominación. Dejando de lado las controversias internas del "socialismo en un sólo pais", por razones económicas y geo-políticas de conservación y superación del sistema (pp. 42-48) el modelo económico se centraliza piramidalmente dentro de la URSS y países satélites y la industria pesada se convierte en el "objetivo prioridad-uno", casi un tin en sl mismo (p. 18), aplicando el "principio residual", dirá Gorbachev al resto de necesidades sociales. No hay duda de que hasta la muerte de Estalín, 1953, la URSS es la "empresa-lider que impone las reglas del juego económico y político. El modelo de "inversión extensiva" (pp. 17-20), más adecuado a la estructura de recursos y tecnología soviélica de aquella época, se impone a paises industrialmente más avanzados (Alemania Oriental, Checoslovaquia, ¿Polonia?...) que hubieran avanzado más rápidamente con un sistema de "inversión intensiva", recomendado oficialmente en la Reforma-Liberman y hoy en la Perestroika de Gorbachev. También al interior del Comecon, por razones obvias, de tamaño y poder de discusión se impone la URSS, a veces con ventajas y a veces no tanto para los miembros asociados. ${ }^{11}$ Dadas las estructuras planificadas del comercio exterior de estos países y las condiciones restrictivas del "rubloIransferible", pero no libremente "convertible", se irán generando flujos crecientes de intercambio comercial y financiero entre el Esle-Oeste, con monedas fuertes convertibles; juegan además olras razones de especialización económica y adquisición de nueva tecnología.

Al inlerior del bloque socialista hay dos momentos en que el "efecto dominación" resiente respuestas más que asimétricas. En 1948 Yugoeslavia rompe con el bloque soviético; y en los años 1955-1956 fuertes convulsiones en Checoeslovaquia, Polonia y levanlamiento armado en Hungria. A ello se anadiria bien pronto el dislanciamiento y 
guerra fría por parte de China. Diez anos más tarde, 1965, el intento oficialmente proclamado de reestrucluración económica, Reforma Liberman, seguido por el desatinado suceso de la invasión a Checoeslovaquia (Primavera de Praga, 1968), de acuerdo al principio de "soberania limitada" (prolocolo del 3-8-68, al momento de la invasión), unánimemente criticada por los partidos comunistas y socialislas europeos ${ }^{12}$.

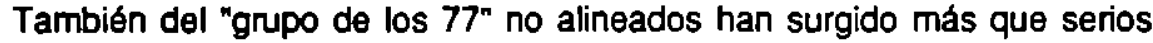
reproches, especialmente contra la URSS, en relación a las estructuras de intercambio y ayuda a los paises del tercer mundo, estando China y la misma Rumanla entre los fiscales de este juicio. ${ }^{13}$

Con bastante objetividad y los datos pueden multiplicarse, el eleclodominación" ha ejercido su poder al interior de ambos bloques y en ambos ha generado réplicas más o menos asimétricas, porque "los mundos son tres" que van a marcar la dirección del futuro. Una frase de Ota Six, coautor de la Primavera de Praga es personalmente significativa. "A largo plazo resultan más firmes los conocimientos científicos que los más fuertes intereses del poder; pero contra la fuerza bruta siempre en la historia ha sido preciso armarse de paciencia"14 Ese más largo plazo parece reflejarto en su reciente obra, "For a humane economic democracy", 1985,15 muy afín al objelivo prelendido por la Perestroika de Gorbachev. Si el efecto-dominación parece razonablemente haber actuado al interior de los grandes bloques, es aún más visible su acción entre las naciones representativas de los mismos, Esle-Oesle, y entre estos y el tercer-mundo. Nos acercamos asl al escenario que contempla Gorbachev desde el capitulo 3: "¿Cómo vemos el mundo actual?"...

La "ruta de los milagros" (milagros económicos en varios paises del Este y del Oeste) pareclan marcar una nueva era, que había encontrado las "sendas del desarrollo". Un best-seller de la época, "La Gran Esperanza del Siglo-XX" de J. Fourrastier, 1963, dibujaba con tonos optimistas la sociedad del futuro: "ninguna civilización serla menos industrial que la nacida de la revolución industrial". Luego del desarrollo del secior secundario-industrial llegaba la época de la civilización del terciario; la "vuelta al hombre", a las disciplinas humanislas, la educación, la cultura los medios de comunicación..., donde el nuevo índice de desarrollo serla "el consumo de papel per-capita". Pese a los datos y apuntes interesantes de este libro, las "ciencias exactas" parecian seguir dominando la producción. La conlabilidad mundial arrojaba cifras optimistas; el PTB mundial aumenta de 0'7 mil billones-dólares en 1950 a $\$ 3.2$ mil billones en 1970. Pero el "eleclo-dominación" se dejaba leer entre lineas. La participación en el producto mundial evoluciona en la siguiente forma:

-1950. EE.UU. $=39,3 \% ;$ MEC $=11,1 \% ;$ URSS $=13.5 \%$; total $=63,9 \%$ -1970 . EE.UU. $-30,2 \%$; MEC $=14,8 \%$; URSS $=16,5 \%$; total $=61,5 \%$ 
Pero la parte allcuola de los países del Tercer Mundo crece imperceptiblemente de $9,1 \%$ en 1950 a $10,0 \%$ en 1970 .

La teorla de la convergencia cede el paso al electo-dominación cuando la "geoestrategia" invade en forma crecienle las economias mundiales. La revista Cahiers Francais dedica, 1981, un número monográlico a las "zonas de comirontación".16 Los dalos estadísticos y sus $\infty$ mentarios son un preámbulo a Perestroika. Para 1978 los gaslos militares en el mundo ascienden a $\$ 400$ mil millones por ano, prácticamente un millón de dólares por minuto. La distribución "porcentual" de los gastos militares era la siguiente:

\begin{tabular}{lccc}
\hline & 1958 & 1968 & 1978 \\
\hline O.T.A.N. & $64,4 \%$ & $56,2 \%$ & $42,8 \%$ \\
\hline -de los cuales los EE.UU. & $(46,2)$ & $(41,1)$ & $(25,6)$ \\
Pacto de Varsovia & $22,1 \%$ & $25,3 \%$ & $28,6 \%$ \\
-De los cuales la URSS & $(20,3)$ & $(23,2)$ & $(25,5)$ \\
-Otros paises industrializados & $3,6 \%$ & $3,8 \%$ & $4,3 \%$ \\
- Tercer Mundo & $4,6 \%$ & $6,2 \%$ & $13,7 \%$ \\
-China & $5,3 \%$ & $8,7 \%$ & $10,5 \%$ \\
\hline
\end{tabular}

El siguiemle comentario dala de hace casi diez anos. "Unir desarmamentlzaclón y desarrollo para resolver dos problemas mayores -la carrera amamentlstica y la pobreza del tercer mundo- es un pensamiento que alegra el espiritu. Pero, como en tantas otras cosas, es más fácll decir lo que se debe hacer qué cómo se puede hacer. Las esladisticas más recientes muestran que los gastos en armamento continúan sublendo mientras que se ensancha la tosa que separa el Norte del Sur. Uno de los principales obstáculos a cualquier limitación de la carrera armamentistica se debe al elevado número de universitarios (flsicos, quimicos, biológos sobre lodo, aunque no exclusivamenle) cuyas investigaciones son financiadas por el presupuesto militar de las grandes potencias. A modo de ejemplo tenemos el dato que más de la mitad de los fisicos y de los ingenieros en el mundo trabajan para el ramo de la delensa. Las cantidades asignadas se aproximan a los $\$ 31 \mathrm{mil}$ millones, suma muy superior a la olorgada para la investigación con fines pacificos. En todos estos paises se han formado vastas burocracias en torno a los asuntos militares. Las presiones formadas por este grupo de militares, industriales, universitarios y burócralas, a fin de mantener e incluso aumentar el nivel de los gaslos militares, son frecuentemente tan fuertes que los políticos no pueden práclicamente sino ceder ante ellas"17. 
Por desgracia, todo este armamenlo no es un "inventario disuasivo". De 1950 a 1978 se hablan librado unas ciento treinta guerras, setenta y cinco de las cuales se calificaban como "confliclos graves". La mayor parte de estas guerras habian estallado al interior de los paises del tercer mundo, que han desembolsado tres veces más en gastos militares de lo que han recibido como ayuda oficial para el desarrollo, sosteniendo así el floreciente comercio internacional de armamento proveniente del hemisferio norte. Algunas guerras se libraron también entre paises socialistas. El valor del armamento pesado entregado a los paises del lercer mundo aumentaba a una lasa de $25 \%$, alcanzando en 1979 la cilra de $\$ 20$ mil millones. De los 54 países productores de armamento pesado, 23 pertenecen al tercer mundo. Ese serial de guerras son "guerras entre sistemas económicos" o en busca de un nuevo modelo económico que ponga fin a las desigualdades sociales.

Todos estos datos estadísticos, que nos introducen en la década de $1970 \ldots$ muestran sulicientemente que estamos pasando de la teorla de la convergencia a la teorla de la irreconciabilidad. En realidad de verdad habla algo más por debajo de toda esta confrontación: entre los dos grandes sistemas (y más en el tercer mundo) a partir de 1970 se está dando un proceso de "convergencia en la crisis mundial". Después de veinte anos de subir por la "ruta de los milagros" (onda larga del Kondralief al alza) todas las economías industrializadas comienzan a dar sefales de cansancio; del "convoy de la inflación" se pasa al carrousel de la estanflación, a la penuria de las materias primas, al deterioro ecológico, a la devaluación-revaluación de algunas monedas fuertes, al reacomodo del sislema monetario, al conflicto petrolero, que además de una carencia importante se entiende como una respuesta agresiva del sur contra el norte... Por lo que toca a las economías socialista el mismo M. Gorbachev hace unas breves relerencias. "En cierta elapa - eso se vuelve particularmente claro en la última mitad de los años selenta- sucedió algo que resulto a primera vista inexplicable. El pais empezó a perder impulso... Al analizar la siluación, primero descubrimos una desaceleración del crecimiento económico. En los últimos quince anos la tasa de crecimiento de la renta nacional declinó en más de la mitad y para comienzos de los ochenta había caído a un nivel cercano al estancamiento económico..." (p. 17). Sin embargo no fue la década de 1970 cuando las economias socialistas sienten el frenazo en sus tasas de crecimiento. En 1956, iniciada la era-Krushchev, el 20 Congreso del Partido inicia un proceso de "remodelación", pero los resultados se hacen esperar. "Las decisiones tomadas por el Congreso ayudaron a través de importantes medidas políticas, económicas, sociales e ideológicas. Pero las posibilidades que emergieron no fueron usadas en su totalidad. La explicación es el método subjetivistas adoplado por el iiderazgo bajo Kushchev. La gestión económica estaba dominada por la 
improvisación. Las deliberadas y cambiantes ideas y acciones de la dirigencia mantenian a la sociedad y al partido en un estado de agitación. Promesas ambiciosas $\theta$ infundadas y predicciones produjeron otra vez una brecha entre las palabras y los hechos..." (p. 47) En las economias socialislas la onda-larga del Kondralief al alza se inició antes que en las economías capitalistas, desde 1930 hasla pasados los 1950; pero los procesos de "remodelación" del sistema, sumado a los esfuerzos del crecimiento "extensivo" generaron también con antelación el trenazo en el ritmo de crecimiento, de manera especial ya entrada la década de $1960 \ldots$

Todo esto llevará al nuevo intento de "reestrucluración" más profundo (perestroika) en la llamada Reforma-Liberman. Valga hacer una pequeha acotación, entre paréntesis: el nombre de Evsei Liberman, prolesor de la Universidad de Jarkov y catalizador de la reforma que lleva su nombre, no aparece citado ni en Perestroika, ni - lo que es más llamativo- en el Informe al Pleno del Partido del 25-6-1987. Una revista alemana editada en inglés, da una pequeña pisla: en febrero de 1983 muere Sun Yefang, inspirado de la actual reforma china. "Sun Yefang, conocido como el "Liberman de China" fue premiado con la más alla distinción poco antes de su muerte. Resulla algo paradójico para la historia económica de las reformas en los paises socialistas, que casi al mismo tiempo, en la primavera de 1983 muere Evsei Liberman "Alone and forgolten"10 También Liberman y su reforma encontrará sus "coniraperestroika". No deja de ser bien llamativo que los mismos problemas que M. Gorbachev planea corregir en el proceso de estancamienlo económico (pp. 17-20) y casi son las mismas palabras aparecen en el Informe de Alexis Kossiguin ante el Pleno de Comité Central del Partido, octubre de 1965: los errores en la planificacón, la baja de la productividad de las inversiones, el deterioro en el proceso de capitalizacón, el retraso en la aplicación de los adelanlos lecnológicos o su poca aplicabilidad, la deficiente calidad de la producción, la pérdida de interés y creatividad a nivel de empresa, el descuido de nuestros economistas en la aplicación de la contabilidad de coslos... M. Gorbachev lo resumen con suliciente realismo. "Es por eso que en la siguiente etapa, cuyo sello distintivo fue la Reunión Plenaria del Comité Central del PCUS de octubre de 1964, el primer paso fue superar esos extremos y combatirlos. Se adoptó un curso de acción hacia la estabilización. Y era un curso bien juslificado. Recibió el apoyo del Parlido y del pueblo. Surgieron algunos resultados positivos. Las decisiones formuladas y adoptadas eran más pensadas y mejor sustanciadas. El comienzo de la reforma económica de 1965 y la Reunión Plenaria del Comité Central de marzo de 1965, dedicado a la agricultura, fueron inicialivas importantes para lograr cambios positivos en la economía. Pero habiendo producido un efecto suslancial, aunque temporario, fueron desapareciendo paulalinamente. La almósfera de complacencia y la 
interrupción del proceso natural de cambio del liderazgo llevó al pals al estancamiento y al atraso. Esto lo he descrito anteriormente. La siluación, mientras tanto, exigla más y más insistentemente decisiones importantes para perfeccionar el mecanismo de conducción económica y social" (p. 47).

Más allá de la apariencia de disconvergencia e Irreconclablalidad militar entre los sislemas se ha ido dando un verdadero proceso de "convergencia en la crisis". Con expresiones, un tanto caúslicas, Andre Gunder Frank, formula esla pregunta: "Se puede cuestionar si la izquierda ha escapado a la crisis de confianza y a la ideológica. Las declaraciones oficiales y oficiosas, según las cuales todo va bien, quizás no sean más que hoja de parra para cubrir una grave crisis ideologica. Esta grave crisis ideologica de la izquierda socialista y del marxismo es un reflejo y contraparte de una crisis económica y política real, y también se manifiesta en los llamados países socialistas, desde la Unión Soviética hasta China, y los palses sociallstas pequenos de la Europa Oriental, del Sudeste Asiático y quizás lambién Cuba. Estos paises están envueltos en la crisis polltica-económica del Occidente -asi como en la suya propia - al menos que ambas sean parte de una misma crisis en un sistema mundial único"19. Andre Gunder Frank cita a continuación algunos testimonios de jeles de partidos socialistas, y que deberlan entenderse desde la nueva traducción del concepto de la "coexistencia pacílica". He aquí dos de las citas. "Dados los amplios vínculos económicos entre los palses capilalistas y sociallstas, dljo Breznhev, los electos nocivos de la crisis actual de Occidente también han repercutido en el mundo socialista"... Y el Primer MInistro de Bulgaria, Zhikov, dijo más: "Es deseable que la crisls por la que atraviesa Occidente termine rápidamente, ya que afecta y crea incertidumbre para la economla búlgara, que hasta cierto punlo depende del comercio con los palses occidentales". Andre Gunder Frank comenta: "Eso es en sl mismo un elemento y manifestación de una crisis muy seria del socialismo y del marxismo; en el pasado y aun durante la última grave crisis del capitalismo, ésta fue bienvenida para los socialistas marxistas, al suponer que sentarla las bases para la posible destrucción revolucionaria del capitalismo y su sustitución por el socialismo. El hecho de que paises socialistas como la Unión Soviética, Bulgaria (sin mencionar a China, que ha entrado en una alianza económico y política con EE.UU. y Japón contra la Unión Soviética) esperen que la crisis termine y colaboren activamente con el capltalismo para superarla (e incluso compitan entre sl para ayudarlo) significa que el socialismo y el maxismo sufren una crisis ideologlca muy grave. Los paises socialistas están claramente comprometidos de palabra, y más aún por sus acciones, con el mantenimiento del capitalismo en Occidente -en efecto desean que prospere y cuanto más 
mejor-; a todos los efectos estos "socialistas-maxistas" parecen haber abandonado la esperanza en el derrumbe del capitalismo en Occidente y las politlcas que comtribuirian a logrario"...20.

Serla de mucho interés analizar sl M. Gorbachev está dando un nuevo gíro a la posición tradicional de la "coexistencia paclfica", dadas las nuevas condiciones de una guerra, sea nuclear o aun convencional, donde ya no habrá vencedores ni vencidos, sino sólo desaparecidos; y donde la guerra deja ya de ser la prolongación de la política por olros medios... Los breves testimonios de Beznhev y Rikhov dejan entrever que ya a partir de 1952 y sobre todo desde 1956, el concepto de "coexistencia pacilica" entraf́a el principio de que "la guerra no es inevilable", anteponiéndose los procesos de negociación como medio para resolver los antagonismos ideológicos. La coexistencia pacífica no excluye la "lucha ideológica", las guerras civiles revolucionarias y las guerras de liberación nacional de los pueblos. El temor es que con las guerras se repita la historia del Prometeo mitológico que, para dar vida al hombre, se robó el fuego de los dioses y luego no pudo dominar al fuego. Porque de acuerdo a declaraciones oficiales de dirigentes sovílicos no habría ni alternativa posible ni divisibilidad: "o coexistencia pacfica o guerra catastrófica" 21. Pero "guerra catastrófica" signitica hoy guerra universal, que no dejarla más que "desaparecidos". La "tecnologla" eslaria lorzando a cambiar la "leorla". Es esto lo que nos lleva a preguntar si $M$. Gorbachev pretende dar una nueva traducción al concepto de "coexislencia pacílica". Aunque el refrán dice que "dos no rinen si uno no quiere", en el caso de la guerra moderna es menester que los dos contendientes moditiquen sus respectivas lecluras de la "coexistencia paclfica", por el bien de ellos mismos y del resto de la humanidad. ¿No habra que leer desde esta óptica el capítulo linal: "Problemas del desarme y relaciones soviélico-norteamericanas"?.

Por otro lado la coexistencia pacílica tiene por objetivo promover los intercamblos con el Occidente, de manera especial en el área económica y tecnológica. Esto explicarla que las afirmaciones de Beznhev y Rikhov obedecen a las nuevas exigenclas historicas, sin negar que pueda haber cierta crisis ideológica al interior de esos palses. El mismo Andre Gunder Frank explica que las economlas socialistas, en general, ocupan un puesio inlermedio en los intercambios económicos-tecnológicos entre los palses industrializados del Occidente y las naciones del tercer mundo. Aunque esta afirmación no se aplique lotalmente a algunos palses soclalistas (Alemania Oriental, Checoeslovaquia...) la siguiente descripción es suficlentemente objetiva. "Los palses socialistas importan tecnologla de Occidente y para pagarla exportan dos terceras partes de combustible y materias primas y una tercera parte de manufaclura. Pero las exportaciones socialistas al "lercer mundo", a su vez, consisten en 
dos lerceras partes de productos manufacturados de bajo nivel lecnológico y sus imporlaciones consislen en dos lerceras partes de malerias primas. Esto es, las economias socialistas ocupan un lugar inlermedio en la división internacional del trabajo: la relación Este Socialista y Tercer Mundo es similar a la relación Occidente Capilalista y Este Socialisla"22 Los datos estadíslicos del comercio internacional para la década de los 1970 muestran la correlación de la "coexistencia pacífica" con la "coexistencia económica". A partir de 1956 el comercio exterior de los paises del Comecon con los paises occidentales aumenta más rapidamenle que sus intercambios con otras naciones; incrementos del $8 \%$ al $10 \%$, que al llegar al quinquenio 1970-1975 crecen a lasas promedios del $25 \%$. Pero a partir de 1976 , debido a la recesión mundial, a las presiones por reducir el peso de la deuda externa con Occidente, derivada sobre lodo de la crisis energética, los países del bloque socialista reorientan sus relaciones comerciales hacia el interior del Comecon, reduciendo su volumen de intercambios comercial-tecnológico con Occidente. Con ello se agudizó más la contracción en ambos bloques, reforzando la "onda larga del Kondratief a la baja", en que nos hallamos todavia asentados. Empalmamos asi con la afirmación de M. Gorbachev: "En cierta elapa - esto se vuelve particularmente claro en la última milad de los anos selenta- sucedió algo que resultaba a primera visla inexplicable"... (p. 17).

\section{La Nueva "convergencla" se llama "Cooperaclón".}

¿Cómo vemos el mundo actual? Con esta pregunla se inicia la segunda parte de Perestroika, el "nuevo pensamienlo y el mundo". Si miramos hacia atrás, la convergencia retrocede ante la carrera a la irreconciabilidad y la controntación ideológica, política y militar. Embarrancados como eslamos los tres mundos en la crisis más larga y profunda Perestroika puede ser un signo de esperanza. El hilo conductor serian tres palabras: "interdependencia, diálogo y cooperación". Desde esta perspectiva, luego de presentarnos un panorama del mundo actual $M$. Gorbachev se dirige a las economias del bloque socialista, a los países del tercer mundo, al conjunto de naciones que se llaman Europa, como "hogar-común" y a la superpotencia de los Estados Unidos. El epilogo, algunos de cuyos párrafos trasladamos al inicio de esle artículo, cierra la propuesla de reflexión conjunta en orden a la reestrucluración del mundo de acuerdo a los parámetros de respeto, liberlad y cooperación mútua de cara al próximo siglo $X \times 1$.

"Me doy perfectamente cuenta de que no lodos estarán de acuerdo conmigo. En realidad, tampoco yo estaría de acuerdo con todo lo que otros dicen sobre diversos temas. Eso hace que el diálogo sea lo más importante' (p. 7). El análisis del mundo actual, sus problemas y sus 
causas, va a diferir sensiblemente en las lecturas que del mismo hagan cada grupo o bloque de naciones. Un hecho reciente lo confirma. La revista "30-Giorni". abril-1988, recoge las reacciones que la enciclica de Juan Pablo-II ha provocado en ciertos medios intelectuales y publicitarios de los EE.UU. En la tercera parte de este documento eclesiástico, "Panorama del mundo actual", que guarda gran similitud con el capitulo tercero de Perestroika, el Papa describe las consecuencias económicas de lo que a su juicio es el factor más importanle, "la existencia de dos bloques conlrapuestos". Para Juan Pablo-II y sus asesores, tanto el "capitalismo liberal como el colectivismo maxista" tienen su arte y su parte en el fallido desarrollo de los pueblos. Y deja planleada la pregunta: "En electo, desde el punto de vista del desarrollo surge espontáneamente la pregunta: ¿de qué manera o en qué medida estos dos sislemas son susceptibles de Iransformaciones y capaces de ponerse al dia, de modo que favorezcan o promuevan un desarrollo verdadero $\theta$ integral del hombre y de los pueblos en la sociedad actual?" (p. 36) -Este equiparamiento de culpabilidad ha provocado acres reacciones en algunos sectores y mass-media norteamericanos. "¿Nosotros como los soviéticos? - Escándalo en los Estados Unidos" - No merece la pena entrar en un comentario, porque también olros norteamericanos aceplan que el Papa tiene loda la razón. En Norteamérica son muy tradicionales las "pellculas de vaqueros" y algunos de ellos piensan que su papel en el mundo es el del "chico bueno", que defiende la libertad y administra la juslicia por cuenta propia...

También Pravda pudiera hacer un artlculo con un tllulo al revés; pero se adelantó $M$. Gorbachev: en Perestroika se siente más realismo y sinceridad. Más o menos explícitamenle Gorbachev reconoce la mútua responsabilidad: los paises grandes, por ser grandes y fuertemente armados, llevan en su interior una propensión al "imperialismo" (p. 161). La Unión Soviética no se exime de su cuota de responsabilidad o culpabilidad; culpabilidad quizás inducida por la carrera armamentística y por su oposición a los neocolonialismo. En este sentido, Perestroika puede marcar nuevos pasos para la paz y el desarrollo, más allá del alcance de la enciclica de Juan Pablo-II. Hay varias razones. Lo primero es la misma novedad: que el premier soviético airee con tanto realismo y sinceridad los problemas internos y externos a la URSS y paises socialislas. En segundo lugar, que siendo él el representante de la otra gran superpotencia ofrezca una mano lendida al diálogo por la paz y el desarrollo. En tercer lugar, que más o menos explícitamente se sefhalan pasos concrelos que ya se estan dando y los que se pueden dar hacia el próximo futuro. Paradoja de tines del siglo XX: M. Gorbachev y Juan Pablo-ll pueden decir: "algo lenemos en común".

El punto de partida es "donde estamos". Un análisis que se inicia sin 
ninguna agresividad a olras ldeologlas o naclones; la Imtenckon es blen diferente: "como decimos en Rusla, mirar las cosas con "ojos nuevos" ( $p$. 157) No serla tan ditílil resumir las ideas de estos párratos, pero un resumen no podrla trasladar el tono literarlo de acercamlento que ellos transpiran: el contenido y la torma de lo que me permito transcribir muestran que $M$. Gorbachev es algo más que un personaje común y corriente.

"¿Cómo es el mundo en que vivimos, este mundo de las actuales generaciones de la humanidad? -Es dlverso, matizado, dinámico y penetrado por tendencias opuestas y agudas contradicclones. Es un mundo de cambios sociales fundamentales, de una revolución clemliflca y tecnologica que abarca todo, de problemas mundlales que empeoran y de cambios radicales en la intormación. Es un mundo en el cual posibilidades inauditas de desarrollo y progreso se colocan codo a codo con la más abyecta pobreza, el alraso y el obscurantismo. Es un mundo en el que hay vastos "campos de tensión"... "El cuadro politico del mundo incluye el considerable grupo de paises socialistas, quienes han recorrido un largo camino en su desarrollo progresivo, en relativamente corto tiempo; la vasta extensión de Estados capitalistas desarrollados, con sus propios intereses, su propia historia, preocupaclones y problemas y el océano de paises del Tercer Mundo, que emergen entre los treinta y cuarenta años, cuando una cantidad de palses de Asla, Africa y Latinoamérica logran su independencia".

"Parece obvio que cada grupo de Estados y cada país tenga sus propios intereses. Desde el punto de vista de la loglca elemental, todos esos intereses deberian verse razonablemente reflejados en la politica mundial. Pero eso no es asl. Más de una vez he dicho a mis interlocutores de los paises capitalistas: veamos y tengamos en cuema las realidades; existe el mundo del capltallsmo y el mundo del soclalismo y también hay un enorme mundo de paises en desarrollo. Este último es el hogar de miles de millones de personas. Todos los paises tlenen sus problemas. Pero los palses en desarrollo los tienen clen veces más que los otros Estados y eso debe ser tomado en consideración. Esos palses tienen sus propios intereses nacionales. Durante décadas fueron colonias, lucharon obstinadamente por su liberación, consiguleron la independencia y quleren mejorar la vida de sus pueblos, usar sus recursos como ellos quieran y construir una cultura y una economla Independientes"... "Nadie puede eliminar el mundo del socialismo, nl el mundo en desarrollo, ni el mundo del capilalismo desarrollado... Una huída al pasado no es la respuesta a lo desallos del futuro, es simplemente Improvlsación, basada en el miedo y la timidez. $Y$ no solamente hemos leido en forma diferente la realidad de un mundo multicolor y multidimensional. No sólo hemos evaluado las diferencias de 
imlereses de los Estados individuales. Hemos visto el problemas principal: la creciente tendencia a la interdependencia de los Estados de la comunidad mundial. Tal es la dialéctica del desarrolio actual. El mundo -contradictorio, social y politicamente diverso, pero no obslante interconectado y ampliamente integral- se va configurando con grandes diflcultades, como si anduviera a tientas a través de un conflicto de opuestos"... "¿Cómo vamos a hacer para poner fin a la inanición y a la pobreza en basta zonas de la tierra?... Pero la Unión Soviética sola no puede resolver lodos estos temas. Y no nos avergonzamos de repetirlo, al pedir la cooperación internacional. Decimos con total responsabilidad, dejando a un lado las falsas consideraciones de "prestigio", que todos nosotros en el mundo actual vamos a depender unos de otros cada vez más y nos volveremos cada vez más necesarios los unos a los olros. $Y$ ya que tal realidad existe en el mundo, y ya que sabemos que estamos, en general, unidos ahora por el mismo destino, que vivimos en el mismo planeta, usamos sus recursos y sabemos que no son ilimitados y que deben ser conservados, y que la naturaleza y el medio ambiente necesitan ser respetados entonces esa realidad nos abarca a lodos. La necesidad de procedimientos y mecanismos internacionales, efectivos y justos, que aseguren la utilización racional de los recursos de nuestro planela, como propiedad de loda la humanidad, se vuelve aún más apremiamte"... "Y aqul vemos nuestra interdependencia, la integridad del mundo, la imperativa necesidad de aunar esfuerzos de la humanidad para el bien de su aulopreservación, para su beneficio hoy, manana y para siempre... La carrera armament/stica, igual que la guerra nuclear, es imposible de ganar. Todos entrenlamos la necesidad.de aprender a vivir en paz en esle mundo, de encontrar una nueva manera de pensar, porque las condiciones actuales son bien diferentes de las que existian hace tres o cuatro décadas atrás. El tiempo está maduro para abandonar los enfoques "imperialistas" en polltica exterior. Ni la Unión Soviética ni los Estados Unidos serán capaces de imponer su voluntad a los demás. Es posible suprimir, obligar sobomar, doblegar o destruir, pero solamente por un cierto perlodo de tiempo.... Tal es nuestro mundo, complejo pero no condenado. Nosotros sostenemos la opinión de que todo puede resolverse, pero cada uno debe replantearse su papel en este mundo y actuar con responsabilldad"... (pp. 157-161).

Esta cila compensa por su contenido el tiempo y el espacio ocupado. Aqul hay muchas tesis novedosas o simplemenle nuevas de cara al futuro, en contraste con to que hemos podido describir en la parte anterior de nuestro comentario. Relacionado con el lema de la carrera armamentislica, uno de los temas centrales de Perestroika, deseo hacer una breve referencia a la pregunta y respuesta que hace M. Gorbachev. ¿¿Qué sucederá entonces con el complejo industrial-militar? (p. 165) si se 
aprueba el desmantelamiento y la reducción del arsenal armamentistico... La respuesta nos remite a los Irabajos recientes del Premio Nobel Wassily Leonlief, "quien ha demostrado que el argumento militarista no se sosliene desde el punto de visla económico". Cada trabajo en el complejo industrial-militar cuesta dos o tres veces más que en una industria civil; se podrian crear tres puestos de trabajo. Los sectores actuales de la economía militar están coneclados con la economía civil y hacen mucho por esta úllima. Más adelante se hace referencia a investigaciones cientílicas que Gorbachev propone se realicen en forma conjunta por las grandes naciones: investigaciones en el espacio y en los océanos... con efeclos positivos en los seclores económicos. En 1977, con tinanciamiento de las Naciones Unidas, W. Leontiel y otros cientílicos de varios paises y universidades realizan un Irabajo sobre "El futuro de la Economía Mundial"23; bajo un conjunto de proyecciones alternativas de los estados demográfico, económico y del ambiente, presentan una "matriz intersectorial-mundial", relacionando melas de desarrollo y disponibilidad y distribución de los recursos. He aqui un instrumento técnico que puede orientar un proyecto de cooperación internacional.

El "Nuevo Pensamienlo Político" (p. 161) es la consecuencia práclica y obligada en cada grupo de naciones, en un marco-ambiente de mútuo respeto. "La genle está cansada de tensiones y confrontaciones. Preliere buscar un mundo más seguro y confiable, un mundo en el que cada uno pueda preservar sus punlos de vista lilosólicos, políticos e ideológicos, y su forma de vida propios". A medida que se avanza en la lectura de Perestroika se comprende por qué "Perestroika" significa y demanda una "revolución". Quedarse en la primera parte del libro y dejar que los soviéticios realicen su perestroika, es dejar sin solución los problemas más graves del mundo. Al interior de Rusia M. Gorbachev ha recibido un fuerte apoyo y algunas de las numerosas cartas han sido integradas en el libro. En nuestro medio demócrata-crisliano vale la pena Iranscribir la carta de un ferviente ruso. "Soy un devolo calólico. Cada domingo voy a la iglesia y pido a Dios que se detenga y no casligue al mundo por sus pecados. Se que usled es aleo, pero a través de sus esfuerzos, ha demostrado que muchos creyentes tienen algo que aprender de usted. $Y$ quiero que sepa que cada domingo yo estoy en la iglesia desde las nueve de lā mańana hasta la una de la tarde, rezando por usted y su familia" (p. 78). No sé si Gorbachev es o no ateo, pero por el lenor de esta carla sí parece que es un buen cristiano. El premier soviético ha recibido lambién el apoyo de grupos internacionales de cientílicos, escritores y personalidades de la cullura. M. Gorbachev cita expresamente la reunión con una delegación de cientíticos ganadores del Premio-Nobel; el Foro Internacional de Moscú para un mundo libre de 
armas y la supervivencia de la humanidad; la Internacional de Médicos para la prevención de la guerra nuclear; la Federación Mundial de Sindicalos de Trabajadores; el Congreso Mundial de Mujeres.... (pp. 177184) La "mano de Moscú (p. 175) parece indicar el camino hacia "nuevas relaciones" (p. 192).

El nuevo pensamiento político intentará generar nuevas relaciones. En primer lugar, nuevas relaclones con los paises soclallstas. Aunque se hable de un "bloque socialista" no se trata en realidad de un conjunto homogéneo, ni por su desarrollo económico ni por su interpretación del modelo socialista. Con suficiente prudencia M. Gorbachev hace mención del distanciamienlo de Yugoeslavia, China y Albania, asi como a los hechos confticlivos en Hungria, Checoeslovaquia y Polonia. El Consejo de Ayuda Económica Múlua (CAEM) realiza una función de integración económica, sin cerrar autárticamente las tronteras al comercio con Occidente. Lo importante en esle momento es senalar la novedad de las declaraciones oficiales y convenios interestatales públicamente pactados, a modo de efecto-demosiración de las tendencias aperturistas. El caso más llamativo -y el más recienle al momento de redactar estas páginas es la Declaración Soviético - Yugoeslava, tirmada en Belgrado el 18 de marzo de 1988. Yugoeslavia se desprende del bloque soviélico en 1948 y bajo el liderazgo del Mariscal Tito inicia un modelo de aulogestión empresarial muy en contrasie con el modelo centralista de la era estaliniana. La Declaración de Belgrado trasciende de lejos el concordato firmado por Krutchev, 1955-1956, afirmando el fin del acoso soviético a Yugoeslavia y a su presidenle Tito; evita anteriores claúsulas que sonaban a subordinación de los intereses nacionales a la "solidaridad intemacional y a la lucha común contra el capitalismo y el imperialismo". El respeto a la "libertad nacional y a la igualdad de derechos" queda bien clarilicada. "Yugoeslavia y la URSS confirman su disposición a desarrollar y enriquecer sustancialmente sus relaciones desde el principio de independencia, igualdad y no ingerencia, la responsabilidad de cada partido a la clase obrera y al pueblo de su propio pais, y el respeto a los diferentes caminos de consinuir el socialismo y establecer sus posiciones internacionales".

Esta declaración firmada por $M$. Gorbachev es una condena de la doclrina Bresnev, o hegemonia limitada de los paises socialistas y trata de desembarazarse de otros residuos propios de la era estaliniana. "En el nuevo documento ambas partes resaltan el respeto mútuo a la independencia, la soberania, la integridad nacional y la no ingerencia sin exclusiones. Anade que nadie tiene el monopolio de la verdad y nadie tiene la intención de imponer al otro concepciones propias sobre el desarrollo social. Afirma el compromiso de ambos con la política de independencia e igualdad de derechos de los pueblos, independien- 
temente de su tamaño y poder, de su sistema socio-polílico, de las convicciones que lo guien, de la forma y naturaleza de sus alianzas internacionales y su posición geográlica"24.

Este documento parece ser el nuevo patrón de conducla en las relaciones con olros paises socialislas. En Checoeslovaquia, hace poco reacio a los lineamienlos de Perestroika, depueslos recientemente (noviembre de 1987) el orlodoxo Gustav Husak, e instalado el aperturista Milos Jakes, se facilitan no sólo las nuevas lineas democráticas sino también las nuevas relaciones que logren cicalrizar las heridas que ponen fin a la Primavera de Praga, 1968. Los hechos polacos de 1988 se han seguido con mayor respelo que en 1980; pero las presiones internas laborales heredadas del pasado asi como la pesada deuda externa están relrasando el proceso. Dejando de lado la independiente Albania, y su radio Tirana, el caso más complejo y más Iranscendental por resolver son las relaciones sino-soviéticas. En la presente década China ha iniciado su "nueva vía al socialismo" bajo la dirección del Ires veces marginado y tres veces rehabilitado Deng Xiaoping. También ellos se proponen impulsar una prolunda reforma (gaige) de las eslucturas politicas del pais, que acompańe su apertura (kailang) hacia luera. "Signo de los tiempos, dice E. Mandel, el nuevo movimiento democrático chino ha elegido como bandera de la quinla modernización la DEMOCAACIA, de la cual depende la realización de las otras cualro (modernizaciones) cientilicas y económicas". 25

Las divergencias sino-soviélicas, aparte de representar vias diferentes del socialismo que las respeclivas perestroikas pudieran acercar, conlienen elementos de confronlación geoestratégica. La reunión cumbre que Gorbachev solicilara a Pekin queda en suspenso mientras no se realicen algunos signos externos de mayor amistad: que la URSS relire el cerco militar y nuclear con que tiene rodeada a China por tierra y mar; que las tropas de Vietnam se reliren de Camboya y que la URSS relire sus tropas de Alganistan. China ha venido realizando convenios comerciales y tinancieros con paises del Occidente, amén de Japón, y espera poder realizar inversiones multimillonarias si la banca comercial se cura del susto de la deuda exlerna del tercer mundo. Estas florecientes relaciones con Occidente, que responden al relrán chino, "el enemigo de mi enemigo es mi amigo", van a requerir de la dirigencia soviélica signos y esluerzos superiores a los propueslos en la Declaración de Belgrado.

Otra área de aplicación del "nuevo pensamienlo" son las relaciones con el tercer mundo, tema central en Perestroika. En el diálogo con Occidente el bloque de los paises socialistas tienen la ventaja comparativa de no haber ejercido en el pasado un colonialismo políticoeconómico sobre paises del lercer mundo. Diriamos que en esle 
terreno M. Gorbachev juega con el vienlo a favor, pero también con el sol en contra. Porque si los países capilalistas del norte han pecado aclivamenle por el abuso de su poder de dominación, lambién los paises del bloque socialisla tienen su cuola de responsabilidad "por omisión". Sus críticas a la explolación internacional han sido fuertes y razonadas. Admitido la verdad del hecho, con lodo los paises socialistas no han quedado fuera de la crítica a su exigua ayuda inlernacional que no ha alcanzado el pactado $1 \%$ del Produclo Nacional. El programa de Manila, 1976, elaborado por "el grupo de los 77 " pretendia incrementar esta ayuda exlerna, que en el caso del bloque socialista no sobrepasaba del $0^{\prime} 13 \%$ o el $0^{\prime} 25 \%$ del PNB. China y Rumania, perlenecienles enlre olros al "grupo de los 77 " fueron de los que acusaron más agresivamente al resto de paises socialistas europeos por mantenerse al margen del "diálogo Norte-Sur", iniciado en 1975, con ocasión de la primera Conferencia sobre la Cooperación Económica Internacional".26

No hay lugar para extenderse aqui en las razones que explican, sea del lado de los países del tercer mundo, sea del propio bloque socialista el relativamente escaso volumen de transacciones comerciales $y$ financieras, ligadas con la ayuda externa. Pese al problema de ideologías y modelos económicos diferentes, los paises socialistas deberian revisar su doctrina sobre la ayuda exlerna, bajo lorma de donaciones e inversión, así como una mayor flexibilidad en el sistema de planeación de exporlaciones-importaciones, sin olvidar la calidad y adecuación de los productos para el país destinatario. Estos reclamos emanan de los paises del tercer mundo y caben en la linea de perestroika. Junlo con esto quedamos a la espera de la mútua apertura de Instituciones y Organismos Financieros Internacionales para inlegrar a más países socialistas y de estos para cooperar en las aclividades apoyo y financiamiento externo. No sabemos si la perestroika llegaria tan arriba; mientras lanto hay que forlalecer el papel compensador de las Naciones Unidas, donde los paises del tercer mundo tienen una más numerosa represenlación. En las Insliluciones Financieras Inlernacionales, que mantienen la norma del "caso por caso", llevan las de perder. Por ello, junto con la defensa del rol a desempenar por las Naciones Unidas seria deseable que los paises del bloque socialisla pudieran irse inlegrando lambién a aquellas Instituciones Financieras que pretenden tener un carácler internacional y una función de ayuda en el equilibrio comercial y en el desarrollo social.

Cada capitulo de esla segunda parte ofrece amplio espacio para su análisis, especialmenle a los especialislas del área respecliva. Tal es el tema de "Europa en la politica exterlor sovlética". M. Gorbachev ha sabido locar aqui una tecla "nacionalista": Europa "el Hogar Común". El hisloriador, el político, el artista, el filósolo... y también el economista y el cientifico vibran al unisono anle el recuerdo de una Europa, que, pese 
a sus fronteras y sus guerras, fue el "hogar común de una civilización" bajo multiformes variedades. Ahora Europa "son dos", y a la Europa Occidental la retienen con las riendas bien tensas, desde la otra orilla del Allántico, para que no cabalgue demasiado rápido hacia los Urales. El acta de Helsinki, agosto de 1975, pactaba un acuerdo de múlua colaboración en el área de la seguridad, cooperación económica, cientílica y lécnica, medio ambiente, asl como en otras áreas humanilarias... entre las dos Europas. Sin embargo, antes y después del acuerdo de Helsinki -al que Gorbachev hace repelidas referencias- han surgido trabas de diversa naturaleza que seguirán obstaculizando el intercambio intraeuropeo. Por ejemplo, es diversa la traducción que da al punto quinto del preámbulo sobre la "distribución equitativa de las ventajas y de las obligaciones" y los términos de la "reciprocidad" en los intercambios comerciales. Mientras que en el Este la reciprocidad se queria entender como "ventaja múlua" de los dos intercambistas, en el Oeste se traduce como la "cláusula de la nación más lavorecida" (Art. $1^{\circ} \mathrm{del}$ GATT): esto implica que "Yodas las ventajas, favores privilegios o exenciones concedidos por un pais a otro se extenderán sin condiciones, a todo producto similar originario de o con destino a lodos los paises signalarios". Aunque algunos paises socialistas pertenecen al GATT (Polonia, Rumanía...), no todos aceptan de entrada la aplicación de esta claúsula de reciprocidad así entendida. Por una parte, la naturaleza de su comercio exterior pianificado (exportaciones- importaciones) en cuolas y precios, y por otra parte - - o mismo en distintas palabras - que la cláusula de la nación más favorecida supone un comercio multilateral, un sistema de tarifas que afecta a los precios $\theta$ incluso un libre juego de monedas "convertibles"... más tipicos de economías de mercado, amén de otras diatribas, ha reducido el volumen posible de lales intercambios. Por el lado de la "geopolítica" la iniciativa del Comité de Coordinación (Cocom), 1949, con sede en París y que agrupa a los paises de la Olan, generó una lista de productos estratégicos que los signatarios se comprometian a no exportar a los palses del Esle. Aqui entran en escena algunos embargos eslablecidos por los EE.UU., que el resto de paises ha respelado "menos o más", porque los negocios son los negocios. Coyunluralmenle el acuerdo de Helsinki, 1975, coincide con el punto de contracción de la economia mundial, que derivó hacia una reducción de los inlercambios Esle-Oeste, quedando aún pendiente en algunos países la deuda exlerna que dala de aquella época. Más lactible será, en la línea de Perestroika, la cooperación cientítica en un abanico de investigaciones, no militares, que lavorezcan avances técnicos en sectores de la economía civil o pacifica.

Entre los diversos puntos alines al tema de "europa el hogar común" hay un tema de posible influencia, más sensible y complejo de tratar. Gorbachev no lo trata expresamente aunque si lo rechaza impli- 
citamente, pero sí aparece en comenlario hechos a Perestroika en algunos medios europeos. La "perestroika", en cuanto revolución interna, enuncia: "Más Socialismo Más Democracia". La Declaración de Belgrado. marzo de 1988, admite diversas vías y modalidades de socialismo entre naciones dilerentes, y en sus cláusulas no hace referencia a los "principios intemacionalislas del marxismo-leninismo". Por su parle $M$. Gorbachev, de acuerdo a recomendaciones del equipo de Novosibirsk, ha introducido la norma de alternalivas de candidalos a puestos administrativos y del partido. Más recientemente se ha puesio a deliberación al senfalar un tope de tiempo en las presidencias y dirección suprema del partido; quizás se quiera evilar la imagen un tanto gerontocrática de Bresnev, Chernenko y Andropov. La pregunta, que algunos la traducen como consejo o como paso necesario a dar, es la siguiente: ¿se abrirá la via al sistema parlamentario de Gobierno? -No es sólo el difícil problema de las "nacionalidades" que enfrenta hoy la Unión Soviélica y otros paises del bloque, sino que el propio avance democrálico tiende a convertir en algo "anacrónico el sistema de partido único". Así se expresan algunos representantes de movimientos socialistas europeos para quienes "el Estado del pueblo entero y el partido de todos" son slongans que van perdiendo su signilicado democrático. De hecho la "nomenklalura"27, a que dieron cuerpo, se ha convertido en freno de anteriores perestroikas y puede obstaculizar la presente. En todo caso, en Polonia se ha propuesto la creación de un partido socialista. Volveriamos así a las discusiones de final de siglo XIX e inicios del presente entre representantes de la "social-democracia". El tema es delicado, contraria a la posición oficial, pero no deja de ser cuestionado en otros medios socialistas; frecuentemente la hisloria es más fuerte que las más rígidas teorias.

Era de esperar que el espacio más amplio se reservara al dlálogo con los Estados Unldos. El estilo y tono de acercamiento hace de este capítulo séptimo una leclura novedosa a quien no está acostumbrado a moverse en el área de los acuerdos de paz, y un momento de seria reflexión para los propios norleamericanos, más influenciados por la propaganda nacional. De todas formas han sido norleamericanos quienes han nombrado a $M$; Gorbachev "el hombre del ano en los EE.UU.". No hay agresividad, sino respelo y reconocimento a la hisloria y al papel de los Estados Unidos en el pasado y más en el presente mundial. Las dos superpotencias tienen una gran "responsabilidad" ante el mundo; M. Gorbachev puede hablar de igual a igual. Si los EE.UU. se presenta o la publicidad la presenta como "una brillante ciudad en la cima de una colina" (p. 252), con todo esa ciudad tiene sus luces y sus sombras. Tiene gran poderío, pero tienen también grandes problemas. $Y$ aunque no coincidimos totalmente, dirá Gorbachev, con esa imagen de la ciudad brillante, lampoco la consideramos como el 
"imperio maligno". Es más bien en los EE.UU. donde se atiza la "imagen enemiga" de la URSS, y es eslo lo que está derivando enormes recursos a la carrera armamentística. Hay un engano en los "civiles" que luchan por incrementar el presupuesto armamentistico y en los "militares" que no gustan de paclar tratados de paz, pese a que conocen el poder de destrucción que tienen entre manos. Con un $10 \%$, incluso un $1 \%$, de lo que ya tenemos podemos destruirnos y destruir el mundo. La carrera armamentística es insensata; y también es irracional querer forzar nuevas etapas competitivas con la intención de desgastar la capacidad económica de la URSS y asl lograr su desgradación intema y externa. Este argumento es invalidado por la historia pasada y presenle, y no pretendemos nosolros torzar a nuevas elapas ofensivas. La meta es ir reduciendo los niveles defensivos en ambas polencias y bloques.

Basarse en calegorias agresivas es olvidar que "nosotros y los norteamericanos cargamos con la más grande responsabilidad hacia las naciones del mundo... Estamos totalmente conscientes de la montana de problemas acumulados entre nuestros países; es importante tralar y resolver aquellos que se han acumulado durante anos... Lo más importantes en las relaciones soviético-norteamericanas es no perseguir milos, sino ver los hechos como son... Y procedemos de acuerdo al hecho fundamental de que ni el pueblo norteamericano ni el soviético quieren la autodestrucción. Convencidos de eso, nos hemos consagrado a mejorar las relaciones con los Estados Unidos y esperamos reciprocidad" (p. 264) Esa apertura al diálogo y la reciprocidad esperada introducen el relato, rico en detalles históricos, de las conversaciones sostenidas con miras a la reducción del arsenal convencional y nuclear sobre todo. Exposición de hechos y de signos positivos adelantados por la URSS: rumbo a Ginebra; el programa de desarme nuclear; EE.UU. después de Ginebra, la lección de Chernobyl; Reykjavik; después de Reykjavik; el foro de Moscú...

Para un leclor sereno, aparte de los datos de primera mano aqul expuestos, eslás páginas finales ayudan a reformar "la imagen de Moscú", algo diferente a la de cierta prensa occidental. Al redactar estas páginas estamos en espera y en esperanza de que se llegue a un acuerdo paclado en la cumbre de Ginebra; lambién en los EE.UU. parece darse una presión para que Congreso y Senado den su previo consentimiento a la lirma presidencial. No era este el ambiente a fines del pasado ano, cuando Gorbachev redactaba las página finales dedicadas al "Foro de Moscú: por un mundo libre de armas nucleares y la supervivencia de la humanidad". No podia laltar "un pelo en la sopa". "Tuve un áspero debate sobre este lema con la senora Thatcher. Ella afirmaba que para Inglaterra las armas nucleares eran la única manera de garantizar su seguridad en el evento de una guerra convencional en Europa. Esa es la 
thosofla de la predestinaclón... Supongamos que comenzamos el proceso de desarme, sacamos de Europa los misiles de alcance medio y reduclmos las armas de ataque estratégico en un $50 \%$, $u$ otro porcentaje, mientras usted continúa aumentando sus fuerzas nucleares. ¿Se le ocurrió pensar en cómo quedará a los ojos de la opinión pública mundlal?... (p. 289).Si, como lo esperamos, en Ginebra se da un paso adelante, M. Gorbachev se semtirá satisfecho por el esluerzo que él ha puesto en esta escabrosa senda de la paz. "Pero cuántas barreras se levantaron y se seguirán colocando en el camino del acuerdo" "¡Qué vallas habrá de remover por medio de la razón y el sentido común para superar la mania nuclearl (p. 291).

A terminar la lectura de Perestroika se tiene la impresión de haber convivido con un nuevo pensamiento para el mundo actual. Es una "perestrolka" para el lector. M. Gorbachev no es un pensador, ni un escritor, común y corriente. Habrá partes o delalles con los que uno puede estar en cierto desacuerdo, como lo dice el autor en su prelacio. Pero es un pensamiento nuevo y una larga lucha por la paz, que es la guerra más dificll. Desde esta segunda parte conviene acompanar a $M$. Gorbachev en esa árdua tarea de la perestroika o revolución, que él y la dirigencla soviética ya han iniciado al interior de la URSS. Esla transformación interna será el signo de credibilidad para aceplar su nuevo pensamiento y el mundo actual. Asl parece indicarlo $M$. Gorbachev al presentar su epllogo. "Creemos que los frulos de la reestrucluración harán renacer también las relaciones internacionales, incluyendo las relaciones soviético-norteamericanas. El nuevo pensamiento es un imperativo de la época". (p. 298).

\section{Convergencla hacla la "Democracla".}

$M$. Gorbachev hace una crltica-constructiva del sistema soviélico económico y politico. No hay "perestroika" posible sin "glasnol": no es posible llevar a cabo una reforma sin una transparencia y sinceridad, que incluso podra sonar hiriente a algunos leclores. Decir "critica-constructiva" parecerla algo contradictorio porque toda critica nos suena a destnuctiva. A decir verdad, etimológica y académicamente "criticar" es enjuiciar, someter al juicio rellexivo la realidad. Por eso M. Gorbachev hace aqul una critica constructiva: "todo el mundo necesita de reestructuración", dirá él, Gorbachev revive con orgullo la historia del pueblo soviético; cuántos sacrificios y privaciones, cuánta laboriosidad y entusiasmo para levantar a un pais de las cenizas de una guerra civil e Internacional. El Yactor humano" es la viga transversal que sostiene la historia de la URSS. Normalmente todos los pueblos son buenos y laboriosos, y si a veces algunos pueblos nos caen mal es por culpa de sus gobernantes. También el pueblo de la URSS tiene su historia 
gloriosa: en condiciones de bloqueo, horfandad económica y comínuas amenazas de agresión la nación se reconsinuye desde la cicatrices de la primera guerra mundial hasta el éxito del segundo conflicto: " $Y Y$ qué dónde estaría el mundo ahora si la Unión Soviélica no hubiera bloqueado el camino a la maquinaria de guerra de Hiller? (p. 42).

También la historia de los paises circundanles tiene que preguntarse porqué la URSS nace en la primera guerra, entra en el segundo conllicto mundial, y al firmar la paz se tiene que preparar para esa tercera guerra de la "mania nuclear". ¿Por qué no ver la historia lodos juntos al hablar de los "imperialismos"? -Al mirar hacia atrás M. Gorbachev aprecia los grandes logros, el gran salto de nación atrasada a superpotencia mundial. Si todo esto se ha logrado gracias al sistema y a los hombres del sistema es ilusorio que el Occidente piense que la UASS desea renunciar a su sistema. Con la credibilidad del pasado aparece a la par la glasnot del presente. "Asl es como lue todo hecho. Tal era el destino de la nación, con todas sus contradicciones, incluyendo grandes logros, dramáticos errores y acontecimientos trágicos" (p. 44).

Gorbachev hace una crítica abierta, a disposición de los medios de publicación, dentro y fuera de la URSS: "queremos que nos comprendan"... "Por supuesto que la Perestroika ha sido ampliamenle estimulada por nuestro descontento por la manera en que han funcionado las cosas en nuestro país en los anos recienles. Pero en mucha mayor medida fue impulsada por la conciencia de que el polencial del socialismo había sido poco utilizado" (p. 7) Se pudiera pensar que la perestroika es un nuevo intento de "reforma administrativa", al estilo de la relorma Liberman, de 1965. El título del Informe al Pleno del Comité Central del Partido (25-6-87), "Tareas del Partido en la Reforma Radical de la Administración Económica", pudiera inducir a una interpretación restringida. Hay un adjelivo que califica a esla relorma: ella quiere ser "radical", ir a la raiz. Si en las plantas las raices están abajo, en el organigrama administrativo las ralces están arriba, en la superestructura politica dirigente.

En artículo anterior, ya citado, intenté hacer un recorrido de ese historial de perestroikas y contraperestroikas, desde los afos de la "nueva política económica "hasta el presente, atravesando las décadas del modelo centralista, las discusiones en Occidente, el paso a la descentralización en las reformas de Krutchev-Bresnev, los sucesos checos que ponen fin a la "primavera de Praga" y el momenlo aclual. Tanto en aquél como en el presente comenlario he sefialado que hay una similitud y una perseverancia en las mismas conlradicciones económicas, que allá sef́alara A. Kossiguin en el Informe al Pleno del Partido (oclubre de 1965) y que vuelven a aparecer en el citado Informe de $M$. Gorbachev al Comité Central, en junio de 1987. ¿Por qué esos pro- 
blemas persisten durante anos...? -Releyendo la historia de la URSS (y cualquier pais) se entiende que no hay perestroika sin glasnot. La década 1920-1928 fue una década de acres pero libres discusiones sobre el modelo económico; notorios economislas soviéticos tomaron parte activa en esla discusión y de esos anos dala el debate sobre la posibilidad y la conveniencia de integrar "plan y mercado" en el modelo socialista. Por desgraci a -y para desgracia de la teoría económica- $-\infty n$ Estalin desaparecen las discusiones y desaparecen exilados o purgados estos librepensadores. En el pasado y presente ano se está llevando a cabo un proceso de rehabilitación de numerosas personalidades de aquella época ${ }^{28}$. De nuevo la década 1955-1965 se presenta como primavera luego de un largo invierno; una vez más, economislas, ingenieros, matemáticos... vuelven a expresarse libre y cientificamente. Ahi arranca, por la chispa que encendió un prolesor de la universidad de Jarkov, la llamada relorma Liberman. Con bastante razón opina $M$. Gorbachev que esa reforma no fue radical; se centraba más al nivel de la gerencia administrativa de la economia, en la esfera de relaciones entre Gosplan y Empresas, pero no ascendía hasta cierlos miembros artríticos de la cúspide del sistema. Personalmente estimo, en cuanto valga esta opinión, que la actual reforma económica tendrá éxilos si la revolución democrática alcanza otros niveles; en caso contrario habrá que esperar al siglo XXI.

Por evaluación de textos e información secundaria, la Perestroika de la actual dirigencia soviética se plasma bastante de cerca en estudios que desde 1983 venía realizando el equipo de Novosibirsk. A. Aganbeguian ha sido calificado como el "gurú de Gorbachev" y T. Zaslavskaya ha sido nombrada presidente de la Asociación Soviélica de Sociologia. El eje central del discurso de estos aulores y su equipo es "la importancia del factor humano", que pasa a ser el hilo conduclor de esta primera parte de perestroika. Por lo tanto no es el factor humano el que debe suponerse que funciona de acuerdo a los hilos de la teoria oficial, sino que es necesario reformar y reestructurar las leorias de las ciencias sociales de acuerdo a la exislencia del faclor humano.

El equipo de Novosibirsk decia: "Uno de los obstáculos más grandes al éxilo de una teoría es sin duda la persistencia del dogmatismo... Aunque lodos están de acuerdo que es algo nefaslo, todos continuamos siendo, en la vida, prisioneros de estereolipos intelectuales que utilizamos sin mayor reflexión. La sociología no es una excepción a la regla. Ella plantea muchos postulados, es decir alirmaciones que, aunque no eslén confirmadas por los hechos, no dejan de ser acepladas como irrefutables y ciertos. De esta manera se atirma que en el socialismo el trabajo es una necesidad vital, que la elevación del nivel de instrucción implica ipsolacto una mejora de la actividad prolesional y que el aumento 
de las remuneraciones genera un incremento de la productivldad. Estas proposiciones no son dogmáticas porque sean inexactas (en realided cada una tiene una parte de verdad), sino porque ellas convlerten esta parte de verdad en un absoluto. $Y_{\text {¿Qué sucede cuando se confronta la }}$ teoría con la realidad? - Se observa que para muchos trabajadores ol trabajo es sólo un "gana-pan", que la mejora en la educación no se acompana necesariamente de un aumento de la producción etc... Los dogmas no son inocentes. No solo sustiluyen a verdades blen establecidas, sino que entran en conflicto con las teorlas que puedan amenazarlas... No sin razón, un buen número de investlgadores en las ciencias sociales han iniciado una guerra contra el dogmatismo en los últimos anos" 29.

Es clara la influencia y cercania con varios pasajes de $\mathrm{M}$. Gorbachev. "También en el plano ideológico, el mecanismo de freno origino mayor resistencia a los intentos de examinar constructivamente los problemas que iban emergiendo y a las nuevas ideas. La propaganda del exlito -real o imaginario- iba ganando terreno. Se eslimulaban los elogios y el servilismo, y se ignoraban las necesidades y opiniones de la gente común, trabajadora, del público en general. En las ciencias soclales la teorización escolástica se fomentó y desarrollo. El pensamiento creativo fue expulsado de las ciencias sociales y los juicios y contribuciones superfluas y gratuitas fueron declarados verdades indiscutlbles. Las discusiones científicas y teoricas que son indispensables para el desarrollo del pensamiento y para el esfuerzo creador, fueron castradas. Esas tendencias negativas también alectaron la cullura, las artes y el periodismo, como también el proceso de ensenanza y la medicina, en donde la mediocridad, el formalismo y los elogios estridentes tamblén emergieron. La presentación de una realidad sin problemas fue contraproducente; se habia formado una brecha entre la palabra y la acción, que produjo la pasividad pública y el descreimiento en los eslogans que se proclamaban. Es nalural que esa situación diera por resultado una brecha en la credibilidad: lodo lo que era proclamado en las tribunas e impreso en los periódicos y libro de texio fue cuestionado. La decadencia comenzó en la moral pública: los grandes sentimientos de solidaridad con los demás, que se lorjaron durante los tiempos heroicos de la Revolución, los primeros planes quinquenales, la gran guerra patriótica y la rehabilitación de la posiguerra, se debilitaban; el alcoholismo, la drogadicción y el crimen crecian, como asi también la penetración de los estereotipos de la cullura popular extrana a nosotros, que produjeron vulgaridad, guslos viles y condujeron a ideologlas estériles"... (pp. 20-21)

Capilulo adelante, al desarrollar el tema de "más luz para la glasnot: la perestroika y la intelligentsia" (p. 90) Gorbachev vuelve sobre el lema. "La 
Intellgentsia, incluyendo los intelectuales del partido bolchevique, sufrió enormes, a veces irreparables pérdidas, a causa de las violaciones de la legalidad socialista y de las represiones de los afios treinta. Esto fue también un formidable golpe al polencial intelectual del país... Sin embargo en el periodo de estancamiento tomó forma una situación paradojlca, en la cual nuestra sociedad era incapaz de usar adecuadamente su enome potencial cullural y creativa. Nuevamente la razón fue que el desarrollo de la democracia habla sido artificialmente aminorado. Las prohibiciones de toda clase y el temor a las nuevas propuestas creativas no podian dejar de tener su efecto" (p. 91)

Por estas y otras referencias es clara la crítica amarga que $M$. Gorbachev debe hacer al desmedido centralismo político de la era estaliniana y al servilismo y corrupción de la época más avanzada de Bresnev. El "modelo económico centralizado" era algo conveniente y necesario en el arranque del salio cuantitativo y cualitativo que tenía que realizar la URSS en la década de $1930 . .$. Sin embargo, no a causa del modelo económico, sino por encima de él se generó una cúspide de poder, llamada Nomenklatura, que dió lugar a una "simbiosis de poder politico y económico" no sólo sobre el conjunto de los medios de producción, sino también sobre todos los medios de expresión de la cultura y del pensamiento. Ello fue engendrando una "alienación política" cuya consecuencia ha sido una "alienación económica", aunque esto parezca darle vuelta a la teoría olicial. Por ello la "reforma radical" se endereza a la cúspide. "La conducción del Partido se relajó y se perdió la iniciativa en algunos de los vitales procesos sociales. Todos comenzaron a notar el estacamiento del liderazgo y la violación de su proceso nalural de cambio. En una cierta elapa eslo contribuyó a una acluación muy pobre del Politburó y la Secrelaria del Comité Central del PCUS por el gobierno y a través de lodo el Comité Central y el conjunto del partido. El flirteo politico y la distribución masiva de premios y bonificaciones, a menudo reemplazaban la genuina preocupación por el pueblo, por sus condiciones de vida y de trabajo, por una atmóstera social tavorable. Surgió una atmostera de "vale-lodo" con cada vez menos exigencias de disciplina y responsabilidad. Se hicieron intentos de disimular todo con campanas pomposas y promesas y celebraciones de numerosos aniversarios centrales y locales. El mundo de las realidades colidianas y el mundo de la prosperidad licticia fueron divergiendo más y más... Los principios de igualdad entre los miembros del Partido eran violados frecuentemente. Muchos miembros del partido permanecieron en cargos importantes más allá del control y la critica, lo cual condujo a fallas en el trabajo y a serios actos de incompetencia... Creo que he dicho lo sulicienle como para que puedan darse cuenta de lo seria que era la situación y de la urgencia de un cambio completo. El Partido ha 
encontrado la fuerza y el coraje para evaluar seriamente la situación y reconocer que los cambios radicales y las transtormaciones eran indispensables..." (pp. 21-23).

Se entiende el por qué de la pregunta: ¿una revolución desde arriba? Gorbachev responde: "En la hisloria hubo muy pocas de esas revoluciones" (p. 60) Perestroika viene de arriba "porque nace desde abajo "Representantes de todos los medios culturales prepararon la moral del pueblo para la perestroika: cineastas, escritores, pinlores, compositores, arquitectos, figuras del teatro y periodistas, todos apoyaron sinceramente la reforma. En la esfera de los hechos económicos se ha aprobado legalmente, como una exigencia de libertad creativa, la "economia auxiliar" de pequefios produclores de bienes y servicios en el campo y en la ciudad; con ello se busca no sólo preslar servicios domésticos y personales antes desalendidos, sino también poner fin a la "economia subterránea", que clandestinamente se hacia sustrayendo recursos de las empresas. Hacia algunos anos que Deng Xiaoping habia sugerido esta práctica en la agricultura china, el "ir por su cuenta" en pequenos trabajos lamiliares: "blancos o negros, mientras cazen ratones, buenos son los galos" decia el refrán chino.

Todos estos intentos venian siendo como los respiraderos de una expresión democrática, que buscaba canales más amplios de expansión. "Toda la gente honesta vió con amargura que el pueblo iba perdiendo su interés en los temas sociales, que los trabajadores ya no tenían su estatus respelable, que las personas, en especial los jóvenes, buscaban el provecho a cualquier costo... En sus mejores obras, nuestros escritores, cineastas, productores teatrales y actores tralaron de fomentar la creencia del pueblo en los logros ideológicos del socialismo y la esperanza de un renacimienlo espiritual de la sociedad $y$, pese a las prohibiciones bucrocráticas e incluso a las persecuciones, prepararon la moral del pueblo para la perestroika" (p. 24).

Si el socialismo se define como un "centralismo democrálico", para que la perestroika lenga éxilo es menesler que se dé una "convergencia del centro y de la perileria". Eslo lendrá su traducción en la esfera económica. La relorma de la adminislración económica no es por lo lanto, tal como se interprelo en 1965 y hoy en comentarios a la Perestroika, una evolución hacia el capitalismo, por la mayor responsabilidad en la autogestión empresarial, por el uso de parámelros de precios económicos, tasa de interés, bonificaciones en función del beneficio, que pasa a ser la norma de la productividad, el mayor énlasis en la contabilidad de costos, y nuevos criterios en la selección de las inversiones... Este proceso de mayor descentralización es la traducción de la "democracia en la administración de los medios de producción, que son propiedad socialista". Aqui hay algo paradójico. Llamamos "economias de mercado" a 
las economias del Occidenle y "planificadas" a las del Este. Si profundizamos en las características esenciales del socialismo, "propiedad social de los medios de producción' y las nuevas relaciones de cooperación y distribución que de aquella se derivan, tenemos que deducir que el "mercado" pertenece a la esencia del socialismo y que sólo en el socialismo el mercado puede servir de orientación y control del plan. "Mercado socialisla" no signilica "supermercado final" de cosas algunas útiles y otras inútiles; "mercado socialisla", expresado brevemente, signilica y comprende todos los componenles de una columna de malriz interseclorial (coeliciente técnicos) y las dos partes inlegrantes de la correspondiente fila, demanda intermedia y demanda tinal. Es una aproximación descriptiva. El Plan o Gosplan, que procura el crecimiento del largo plazo, fija los índices generales y sectoriales, así como los medios económicos para alcanzarlos. Las empresas llevan a cabo la "optimización de los recursos". Esle es el modelo de administración democrática de los medios de producción sociales. Si el "Centro quiere adminislrar 10do, ni siquiera se adminislra a si mismo. Y socialmente no dejaria espacio a la participación creativa de las empresas y sus trabajadores, ambos a dos socialistas Por lo tanto ni la Retorma Liberman ni la aclual Perestroika es una desviación al capitalismo, donde el mercado ni siquiera logra orientarse a sí mismo. Perestroika es un paso más hacia el socialismo.

En la correspondencia económica entre Sweezy y Bettelheim, luego de la invasión a Checoslovaquia, 1968, ésle último escribia: "Pueden existir una planilicación y un plan burgueses, lo mismo que pueden existir una planificación y un plan prolelarios o socialislas... Idenlificando plan con socialismo y mercado con capitalismo (lo cual es cierto como tendencia) se ayuda a la burguesía - y especialmente a la burguesia soviélica- a ejercer su dominación al abrigo de un plan, en cuyo nombre retira todo derecho de expresión a las clases exploladas y con cuya ayuda puede agravarse aun más la explotación de las masas... Cuando un plan no es este concentrado (iniciativa de las masas) es un plan burgués y no un plan socialista; no es lo contrario del mercado, sino su complemento o su sustituto provisional. Esto que acabamos de decir ha sido en la práclica ignorado durante mucho tiempo (incluso por mi mismo)"..., afrade Bettelheim. ${ }^{30}$.

Esla cita, algo novedosa, viene a indicar que lambién hay una serie de áreas donde la teoria económica socialista viene cojeando desde hace un tiempo. Un párrato de E. Liberman a la revista The Economist, que comentaba ef regreso de la URSS al capitalismo, sirve de bolón de muestra. "La resistencia, que según ustedes, encontraron mis propuestas en 1962 no se debe a conservadurismo de algunos individuos, sino al hecho de que nuestra ciencia económica no ha elaborado sufi- 
cientemente este complicado problema en su conjunto. Pese a los argumentos de mis adversarios, he tenido la oportunidad de experimentar mis propuestas. Estas posibilidades de experimentación se han ampliado actualmente, pese a la oposición contraria en algunos economistas, por muy alla que sea su posición"... ${ }^{31}$ La verdad es que E. Liberman y su reforma encontrarán dos obstáculos, las resistencias en la cúspide y el retraso en la teoria económica; y E. Liberman desaparecerá de la escena, 1983 "alone and forgotten".

No hay lugar ni es el momento de extenderse en algunos punlos donde la teoría económica socialista trata de recuperar el tiempo perdido. Un punto clave es la teoria de los precios, donde se ha venido navegando con un sólo remo, bien amarrado al "valor de cambio", pero donde la práctica micro y macroeconómica necesila integrar lodos los componentes sociales del "valor de uso" (Comité Diarchenko"); múltiples han sido los intentos de reforma en esta área ${ }^{32}$. El mismo Gorbachev senala que aún queda camino por recorrer, al locar el problema de la "contabilidad de costos". (p. 99) "Se tardará dos o tres anos en preparar una reforma de la formación de precios y de los mecanismos de financiamiento y de crédito y de cinco a seis anos para alcanzar al comercio mayorisia en los medios de producción"... (p. 100) Por la cila de $M$. Gorbachev se percibe que, junto con la reformulación teórica y práclica de los precios, se plantea todo el amplio espectro del papel activo de la moneda en los circuilos internos, escriptural y fiduciario, asl como su adaptación en el mercado internacional de transferible a convertible. Eslo enlaza con el problema de la mayor flexibilidad de la planificación del comercio exterior y de las posibilidades y consecuencias derivadas de la integración en Instiluciones Financieras Internacionales, con vistas, al menos, a dar un mayor soporte a la ayuda exlerna a los países del tercer mundo.

Perstroika y Glasnot es un juego de luces y sombras en la sociedad soviética; por ello no es fácil leer, con ánimo sereno, esta primera parte del libro. Unos prefieren quedarse en las sombras para confirmarse en sus propias sombras; otros preferirán decir que "perestroika socava las bases del socialismo" y citar bellas páginas escritas en el pasado o presente siglo, pero no muy de acuerdo a la historia. M. Gorbachev ha tenido la audacia de ser honrado con las luces y con las sombras. Por eso este libro ha despertado la gran curiosidad y la gran admiración con respeto. M. Gorbachev ha sido honrado al decir la verdad a la Unión Soviética y al resto del mundo. En todo este proceso ya iniciado Gorbachev va a encontrar una ayuda o una competencia, según se le mire. También el otro subcontinente asiático, la China de Deng Xiaoping ha inciado, quizás con menos repercusión en nuestro occidente, una reforma política interna y una apertura externa, bajo la bandera de la 
"democracia". El socialismo quiere caminar hacia el socialismo: "una convergencia hacia la democracia".

Este comentario no quisiera ser un entretenimiento académico sobre hechos y dichos de la Unión Soviética y del reslo del mundo anónimo. El mensaje de Perestroika se dirige a nuestro estrecho istmo y pequeno pais, donde hay más de irreconciabilidad que de convergencia, más de efecto-dominación que democracia, donde hay más sombras que luces, donde hay más publicidad que hechos..., y donde, robando el tilulo a Ota-Six, lenemos que oplar "For a humane economic democracy".

Lic. Francisco Javier Ibisale.

\section{NOTAS}

1. Gorbachev M.: PERESTROI KA. Nuevas ideas para mi pals y el mundo". Edit Diana. México, 1987. Las páginas que se cilan (entre paréntesis) se refieren a esta edición.

2. Ibisate Fco. J.: "Perestroika: nuevas ideas para mi páis y el mundo". ECA. Abril de 1988.

3. Gorbachev M.: -Tareas del partido en la reforma radicel de le administración económica". Edit. Novosti. Moscú, 1987

4. Parls Carlos: "El mundo según M. Gorbechev; propuestas de Gorbechev para evitar catástroles". El Pals, 17 de enero de 1988.

5. Ibisate Fos. J. Articulo citado. ECA. Abril, 1988.

6. "Le pouvoir soviétique a la recherche d" un consensus: Le programme de rélormes de Mikhail Gorbatchev. La Documentation Francaise. Problemes Politiques et Socieux. 1987.

7. Ibisale Fco. J.: "La crisis de 1970-1980... ¿es realmente une crisis? ECA, Sept. Oct. 1992; pp. 897-910.

8. Tinbergen J.: ¿Presentan las economlas comunistas y las libres una pauta convergente? Y Prybyla J.: "Convergencia de los sistemas económicos oecidental y comunista: estimación critica". Recopilación de Borstein M. en "Sistemes Económicos Comparados". Amorrortu, 1969.

-Galbraith J. K.: "The new industrial state", 1967.

-Sehenk K.E.: "Economic systems: between convergency and irreconciability". Economics. Tubingen. Vol. 7. 1983. pp. 137...

9. Ibisate Foo. J. Artlalo citado: "La Relorma-Libeman", 1865: un intento olicial de "perestroika"..

10. Perroux F.: "L'economie du XXeme siécle. P.U.F., Parls, 1964; pp. 26...

11. Lagigne M.: "Les économies socialistes..." "Les Rúlations économiques entre les etars socialistes". Edit. Armand-Colin; Paris, 1979; pp. 345-386.

12. Ibisate Foo. J. Antlaulo citado. "La Primavera de Praga y la Contraperestroika",

13. Lavigne M. Opus cit. pp. 397-404.

14. Ota Sik.: "La tercerta vla". F.C.E. Móxico, 1977; p. 10.

15. Ota Sik.: "For a humane economic democracy". Edit. Praeger, New-York. 1985.

16. Cahiers Francais. "Głostraßguie et Économie mondiales. Janvier, 81.

17. Opus cit. p. 15...

18. Erling J.: "Five years of economic relorm in China: partachievernent and future prospects". Economics. Tubingen. Vol. 129, 1984; p. 116.

19. Andre Gunder Frank: "El desarrollo de la crisis y la crisis de desarrollo". Comercio Exterior, México, 1980, 3; pp. 238-239. 
20. Andre Gunder Frank. Art. cit. p. 239.

21. Cahier Francais. Janvier-1981. "La stratégie de L'Est.; pp. 66-67...

22. Andre Gundor Frank opus cit. p. 239. Con mayores detalles estadísticos y exlicativos, en Lavigne M. Opus, Cit. pp. 383-409.

23. Leontief W. et Alii: "EI luturo de la Economla Mundial". Naciones Unidas. Siglo XXI. 1977.

24. Tertsch H. "La muerte de la doctrina Bresnev". El Pals, Madrid; 11 de abril de 1988; p. 4.

25. Mandel E,:: "La Crise: La réinsertion de la Chine dans le marché mondial". Edit. Champs Flammarion. Paris, 1985. p. 202.

26. Lavigne M.: Les économies socialistes: les relations entre les pays socialiste et les pays en voie de développement". pp. 397-404.

27. Voslensky.: "La nomenklatura". Edit. Loissirs. France. 1980.

28. Medvedev R. "El comunismo soviético recupera al lavorito de Lenin: la rehabilitación de Bujarin y Rikov.. "El Pals, Madrid, 12-2-1988; p. 4.

29. Problémes Politiques et Sociaux. La Documentarion Francaise.. Opus cit.; p. 5.

30. Sweezy P. y Bettelheim Ch.: "Algunos problemas actuales del socialismo" Siglo XXI; p. $62-63$.

31. Liberman E.: "Plan y beneficio en la Economla Soviótica". Ariel p. 101.

32. Lavigne M. Opus cit. "La lormation des prix"; pp. 279-297. 